\title{
Las nuevas formas de la actividad administrativa. Participación, ejercicio privado de funciones públicas y gestión privada de servicios publicos
}

\author{
Juan-Cruz Alli Aranguren \\ Profesor Titular de Derecho Administrativo \\ de la Universidad Pública de Navarra
}

Sumario: 1. LA GESTIÓN DEL INTERÉS PÚBLICO Y LA PARTICIPACIÓN. 2. EL EJERCICIO PRIVADO DE FUNCIONES PÚBLICAS. LA AUTORREGULACIÓN. 3. LA GESTIÓN PRIVADA DE SERVICIOS PÚBLICOS EN EL MODELO COMUNITARIO. 3.1. Los servicios de interés general. 3.2. Los servicios de interés económico general. 3.3. Externalización de la prestación del servicio.

En la compleja organización institucional del Estado existe una periferia interna formada por instituciones dotadas de derechos de autoadministración o de funciones de competencia y control estatales delegadas por el Estado (universidades, sistemas de seguridad social, cámaras de comercio, fundaciones, etcétera) y otra externa con relaciones complejas con las Administraciones, que son organizaciones, confederaciones, grupos de intereses, asociaciones, etcétera necesitados de regulación que integran la sociedad civil. Su núcleo «lo constituye una trama asociativa que institucionaliza los discursos solucionadores de problemas, concernientes a cuestiones de interés general, en el marco de espacios públicos más o menos organizados» ${ }^{1}$.

En los últimos tiempos del Estado de bienestar y en los primeros años de la globalización se ha producido el incremento de la presencia de los ciudadanos en la toma de decisiones por medio de la participación. Hasta el punto de asumirse que la determinación y búsqueda del interés general no es exclusiva de los poderes públicos, sino que también corresponde hacerlo a lo que se ha llamado la «sociedad civil» y las organizaciones en que se vertebra aquella y en las que se socializan las personas. Como expuso HABERMAS, «desde fines de los años sesenta se acumularon las evidencias a favor de una estimación mucho más precavida y reservada. El sistema administrativo sólo parece poder operar dentro de un espacio de acción extremadamente estrecho; parece quedar restringido, atenido y obligado a la forma de movimiento más bien reactiva que representa una política tendente, no tanto a planificar como a evitar la crisis $»^{2}$. En la sociedad neocorporativa de la autorregulación se ha producido una zona gris entre el Estado y la sociedad que es la de las acciones concertadas, las mesas redondas, los organismos de coordinación en la que aquel ha perdido el protagonismo de épocas anteriores, convirtiéndose «en un sub-

\footnotetext{
${ }^{1}$ Habermas, J., Facticidad y validez, Madrid, Trotta, 1998, cit., p. 447.

${ }^{2}$ Habermas, J., Facticidad..., cit., p. 411.
} 
sistema entre otros subsistemas que ya no puede pretender ningún primado en la sociedad [...] descargado de la función de integrar a la sociedad en conjunto. [...]». La visión neocorporativista configura subsistemas autónomos activos e interdependientes, que no extraen la racionalidad de la validez de lo universal, sino de una sintonización reflexiva de lo particular, que conduce a un Estado de la supervisión del que forma parte el Derecho reflexivo ${ }^{3}$. El Estado supervisor negocia con los sistemas funcionales de la sociedad, con las organizaciones, asociaciones, etcétera que se sustraen de la regulación impositiva para hacerla consensuada, de modo que «la soberanía del Estado queda enterrada en la medida en que corporaciones socialmente poderosas participan en el ejercicio del poder público, sin quedar sujetas a las responsabilidades que son habituales cuando se trata de órganos del Estado» ${ }^{4}$.

Por otra parte, esta presencia ha alcanzado al ejercicio privado de funciones públicas, por medio de fórmulas de Derecho convencional o reflexivo, y a la gestión de los servicios públicos que han dejado de ser una manifestación orgánica para distinguir entre la titularidad de la competencia y la gestión del servicio, separando esta de aquella al encomendarla a personas físicas o jurídicas distintas de la Administración competente. Mucho más cuando por influencia del Derecho comunitario de la competencia los servicios públicos de contenido económico han de sujetarse a sus reglas para prestarlos en el régimen de libre competencia y circulación de personas, bienes y servicios que es propio del mercado común. Como señaló MuÑOZ MACHADO, «se nos vuelve a cambiar el Estado, pero ahora por causa del adelgazamiento sufrido del sector público y la reducción de algunos servicios públicos tradicionales: unos se achican, otros se liquidan y el resto, en fin, parece estar indudablemente abocado a asumir un régimen jurídico, respecto de su organización y funcionamiento, completamente nuevo» ${ }^{5}$.

En esta misma dinámica, aunque tiene mayor antigüedad, se ha de situar el incremento de la utilización del Derecho privado por la Administración en el proceso que se ha denominado la «huida del Derecho administrativo». Como una manifestación más del mismo, se ha de destacar la incorporación de fórmulas convencionales para terminar los procedimientos administrativos ${ }^{6}$, la transacción o el arbitraje ${ }^{7}$, o para adoptar decisiones, como es el caso de los convenios urbanísticos.

\footnotetext{
${ }^{3}$ Habermas, J., Facticidad..., cit., pp. 422-424.

${ }^{4}$ Habermas, J., Facticidad..., cit., p. 519.

5 Muñoz Machado, S., Servicio público y mercado, I, Madrid, Civitas, 1998, pp. 17-18.

${ }^{6}$ Sánchez Morón, M., Trayter, J. M. y Sánchez Blanco, A., La apertura del procedimiento administrativo a la negociación con los ciudadanos en la Ley 30/1992 de Régimen Jurídico de las Administraciones Públicas y del Procedimiento Administrativo Común, Oñati, IVAP, 1995.

${ }^{7}$ Huergo Lora, A., La resolución extrajudicial de conflictos en el Derecho administrativo. La transacción, el arbitraje y la reforma de los recursos administrativos, Bolonia, Real Colegio de España, 2000. Rosa Moreno, J., El arbitraje administrativo, Madrid, McGraw Hill, Madrid, 1998.
} 
A este conjunto de hechos se le ha denominado, genéricamente, privatización entendida como «toda iniciativa pública que persigue reducir la intervención pública y aumentar la eficiencia económica, abandonando lo público y recurriendo a lo privado en diversos campos: titularidad de la actividad, forma de gestión, régimen de propiedad, régimen jurídico y forma de financiación ${ }^{8}$. También se ha calificado como tal a la participación de entidades privadas en la prestación de los servicios públicos, a la realización y gestión de las infraestructuras y a la eliminación de los monopolios creados por el Estado y gestionados mediante empresas públicas. En este último caso se ha actuado por la reducción de las aportaciones presupuestarias, los privilegios fiscales o los créditos bancarios especiales en su régimen e intereses, por la mejora de su competitividad para actuar en el mercado, por su reestructuración y transformación en empresas mercantiles con capital público mayoritario o por su paso a manos del capital privado por la desinversión pública, que en muchos casos se ha realizado a favor del personal de la propia empresa o del «capitalismo popular».

Sin embargo, se ha de precisar el significado, porque en él se encuadran actuaciones muy distintas en su contenido, alcance y régimen:

a) La privatización por la transferencia de la propiedad de empresas y activos económicos al sector privado.

Durante el periodo del Estado social se configuró un importante sector público estatal, agente directo en la actividad económica, a la que aportaba bienes y servicios por medio de la actividad económica e industrial de las empresas públicas. Estas empresas y actividades se transfieren al sector privado por la enajenación de las empresas, de las participaciones en el capital social, de sus activos, perdiendo la Administración su propiedad e influencia en ellas. Este acto agota por sí mismo el proceso e implica una descapitalización del Estado por la desamortización industrial que realiza9 .

b) Transferencia al sector privado de actividades o funciones públicas.

Por efecto de las nuevas concepciones de carácter neoliberal que invocan la eficacia y eficiencia económica, la reducción del gasto público y

\footnotetext{
8 Ariño, G., Cuétara, J. M. de la y López de Castro, L., Principios de Derecho público económico, Granada, Comares, 1999, p. 439. ARIÑo, G., Economía y Estado, Madrid, M. Pons, 1993; «El retorno a lo privado: ante una nueva encrucijada histórica», en Anuario de la Facultad de Derecho de la Universidad Autónoma de Madrid, 3, 1999, pp. 27 y ss.; Privatización y liberalización en España: balance y resultados (1996-2003), Granada, Comares, 2004. GamiR, L., Las privatizaciones en España, Madrid, Editorial Pirámide, 1999. Martín-Retortillo, S., «Reflexiones sobre las privatizaciones», en RAP, 144, 1997, pp. 7 y ss. Trigo Portela, J., Veinte años de privatizaciones en España, Madrid, Instituto de Estudios Económicos, 2004. Troncoso Reigado, A., Privatización, empresa y Constitución, Madrid, M. Pons, 1997. Guislain, P., Privatisations: un défi stratégique et institutionnelle, Bruselas, Boeck, 1995.

9 Martín-Retortillo, S., «Reflexiones..., cit., p. 26; puso de manifiesto el riesgo de arbitrariedad de estos procesos (p. 29). Por acuerdo del Consejo de Ministros de 28 de junio de 1996 se aprobó el Plan de Modernización del Sector Público Empresarial del Estado y creó el Consejo Consultivo de Privatizaciones.
} 
las políticas comunitarias de libre competencia y prohibición de prerrogativas a favor de las empresas públicas, se ha producido la transferencia al sector privado de actividades o funciones públicas en sanidad, e nseñanza, seguridad, transportes ${ }^{10}$, asistencia social, etcétera con fórmulas distintas ${ }^{11}$ :

- privatización organizativa reservándose la titularidad pública, encomendando la gestión de la función o servicio público a entidades públicas o privadas, de modo que el servicio se presta por modo indirecto (concesión, gestión interesada, encomienda, concierto, sociedad de economía mixta) en una forma tradicional en los servicios públicos ${ }^{12}$, que supone la externalización de la prestación pero manteniéndose la gestión (planificación, dirección, control y evaluación) pública.

- privatización funcional, por pasar al sector privado tanto la titularidad como la gestión de servicios que fueron establecidos y cuya titularidad correspondía al Estado (telecomunicaciones, energía, sanidad, correos, etcétera $)^{13}$.

c) Utilización por la Administración del Derecho privado en la personificación y procedimientos para el ejercicio de funciones públicas, que se conoce como la «huida del Derecho administrativo».

d) Desreglamentación o desregulación por supresión de las normas estatales referidas a un campo o actividad para ampliar la competencia del monopolio público, que serán reguladas por normas de Derecho privado o actuarán en el mercado libre, aunque el Estado pueda mantener competencias

\footnotetext{
10 Organización Internacional Del Trabajo, Consecuencias sociales y laborales de la evolución tecnológica, las desreglamentación y la privatización de los transportes (con inclusión de la aviación civil, los ferrocarriles y el transporte por carretera), Ginebra, 1999; Informe final, 20-24 de septiembre de 1999.

${ }^{11}$ Martín-Retortillo, S., «Reflexiones..., cit., pp. 12-13, distingue entre la privatización material cuando la prestación realizada por el Estado pasa a serlo por un agente social, formal por la utilización por la Administración del Derecho privado (huida del Derecho administrativo) y funcional cuando se transfiere el ejercicio de funciones públicas.
}

12 Morell Ocaña, L., «La organización y las formas de gestión de los servicios en los últimos cincuenta años», en $R A P, 150,1999$, pp. 379-452.

${ }^{13}$ El artículo 1.2 de la Ley 4/1980, de 10 de enero, dispuso que «la radiodifusión y la televisión son servicios públicos esenciales cuya titularidad corresponde al Estado». El artículo 1.1. de la Ley 49/ 1984, de 26 de diciembre, declaró que «la explotación unificada del sistema eléctrico nacional es un servicio público de titularidad estatal». El artículo 69.1 de la Ley 16/1987, de 30 de julio, dispuso que «los transportes públicos regulares permanentes de viajeros de uso general [...] tienen el carácter de servicios públicos de titularidad de la Administración». Conforme al artículo 2.1. de la Ley 31/1987, de 18 de diciembre, se declaró que «las telecomunicaciones tienen la consideración de servicios esenciales de titularidad estatal reservados al sector público». El régimen de la televisión privada fue fijado por la Ley 19/1988, de 3 de mayo, que reguló «la gestión indirecta del servicio público esencial de la televisión cuya titularidad corresponde al Estado» (art. 1). 
policiales de regulación y supervisión a lo que se ha denominado «privatización reglamentada» ${ }^{14}$.

e) Liberalización, que es el concepto más genérico que alcanzaría a todas las actuaciones anteriores y supone eliminar los monopolios, los servicios públicos o las limitaciones al ejercicio de actividades estableciendo un régimen de libertad y libre concurrencia para su ejercicio. Según MuÑOz MACHADO, «procura una reducción de las intervenciones públicas en los sectores económicos fundamentales para el desarrollo de la competitividad y el empleo [...] la aplicación a las relaciones entre empresas del principio de igualdad y de las reglas de mercado, entre las cuales son fundamentales los principios de libre competencia» ${ }^{15}$.

Estas actuaciones no suponen, en sí mismas, el final de uno de los aspectos característicos del Estado social, porque «la reducción del papel del Estado no significa 'eliminación' de dicho papel; significa sólo, como regla general, su transformación; abandono de la actividad estatal directa (servicio, prestación, dación de bienes) y asunción y reforzamiento de la actividad de dirección, supervisión y control». Lo que, genéricamente, se denomina la privatización implica «una profunda transformación de la ejecución administrativa en sentido tradicional, es decir, en cuanto acción sistemática de una organización perteneciente al poder político para producir un determinado resultado programado normativamente, [...] cuyo rasgo más sobresaliente es la vuelta, aunque con perfiles innovadores, a una Administración de policía general del riesgo, como denotan las soluciones en los sectores liberalizados» ${ }^{16}$.

\footnotetext{
${ }^{14}$ Martínez López-Muñiz, J. L., «Nuevo sistema conceptual», en Anuario de la Facultad de Derecho de la Universidad Autónoma de Madrid, 3, 1999, p. 137, lo denomina neorregulación o re-regulación. Soriano García, J. E., Desregulación, privatización y Derecho Administrativo, Bolonia, Real Colegio de España, 1994. El amplio significado de la regulation anglo-americana, que engloba todas las técnicas jurídicas e instituciones de intervención estatal, ha dado lugar a un debate conceptual en Francia: Chevallier, J., «De quelques usages du concept de régulation», en MAILle, M., La régulation entre droit et politique, Paris, L'Harmattan, 1995, p. 71. En los EEUU la desregulación de las telecomunicaciones partió de la decisión antitrust de 1984 y supuso el desmantelamiento de la American Telegraph and Telephon y la supresión de las normas que impedían la entrada de nuevos operadores, estimular la concurrencia y la innovación. En la Gran Bretaña la privatización de British Telecom implicó la supresión del monopolio del operador dominante y la liberalización del mercado manteniendo el poder regulador. En el caso de los medios de comunicación en España, principalmente de la televisión, se partió de la ecuación monopolio público-monopolio político del partido en el poder que legitimaba la cadena exclusivamente estatal, que duró hasta la aceptación de la participación en el servicio público de las cadenas autonómicas y privadas en un sistema mixto, cada día más plural por la presencia de cadenas internacionales facilitada por la nueva tecnología por satélite y digital, así como la influencia mediática y cultural norteamericana como efecto de la globalización, que ha producido un nuevo proteccionismo cultural de los Estados.

15 Muñoz Machado, S., Servicio..., cit., p. 20.

16 Parejo Alfonso, L., «El Estado social administrativo: algunas reflexiones sobre la crisis de las prestaciones y los servicios públicos», en $R A P, 153,2000$, pp. 221 y 231.
} 
Este nuevo régimen está recuperando la actividad de policía, que sustituye a la de servicio público ${ }^{17}$, por la regulación de la concurrencia, la protección del medioambiente, las garantías del sistema financiero y del cumplimiento de los objetivos macroeconómicos y de convergencia derivados de la pertenencia al orden comunitario. Esta policía se limita a las «condiciones de seguridad, salubridad, protección del medio ambiente y localización física en que se desarrolla la actividad económica de que se trata, pero sin entrar en el interior de ésta ni predeterminar las decisiones empresariales ${ }^{18}$. En palabras de MuÑOZ MACHADO, «supone una intervención de los poderes públicos respecto de la actividad y el comportamiento de las empresas [...]. En una economía liberalizada completamente, podría suponerse que las fuerzas del mercado son suficientes para organizar las relaciones entre los que producen bienes y servicios y los que los consumen. Sin embargo, los equilibrios del mercado nunca son perfectos. Se producen fallos, [...] que deben corregirse por los poderes públicos mediante medidas de reajuste. Tratan éstos de preservar los intereses generales. Además, el funcionamiento libre del mercado, conforme a sus excesivas reglas, sin intervención alguna, produce externalidades, efectos sobre otros sectores de la actividad social o económica, que deben corregirse igualmente. Y, finalmente, también es necesaria la regulación para mejorar la información disponible por parte de los consumidores a los efectos de que puedan adoptar decisiones correctas respecto de los productos que usan y consumen ${ }^{19}$.

Se trata de la «regulación de la autorregulación, que da origen a la «regulación regulada» convertida en «un complemento o un sustituto de la regulación administrativa de policía. [...] se manifiesta también cuando los poderes públicos atribuyen concretos efectos jurídicos a la autorregulación», como los habilitantes, los probatorios, los vinculantes y los de cosa juzgada. De tal modo que la autorregulación actúa «como un elemento integrador del ordenamiento jurídico» y mantienen intacto su componente de voluntariedad $^{20}$.

\footnotetext{
17 Villar Palasí, J. L., «La prospectiva del Derecho administrativo», en XI Congreso italo-español de profesores de Derecho administrativo, Barcelona, CEDECS, 1998, p. 615.

18 Ariño Ortiz, G., Principios..., cit., p. 553. Rebollo Puig, M., «La policía administrativa y su singular adaptación al principio de legalidad», en El Derecho administrativo en el umbral..., cit., I, pp. 1365-1397.

19 Muñoz Machado, S., Servicio público..., cit., I, p. 221. Desdentado Daroca, E., La crisis de identidad del Derecho administrativo: privatización, huida de la regulación pública y Administraciones independientes, Valencia, Tirant lo Blanch, 1999, pp. 169-170.

20 Darnaculleta i Gardella, M. M., Autorregulación y Derecho público. La autorregulación regulada, Madrid, M. Pons, 2005, pp. 385-386.
} 


\section{LA GESTIÓN DEL INTERÉS PÚBLICO Y LA PARTICIPA- CIÓN}

Se ha superado la consideración de que la Administración es la interprete exclusiva de los intereses generales. El Estado social y democrático de Derecho y el Estado reflexivo reconocen que existen intereses, expresados por las colectividades sociales, que participan del interés general. De tal modo que no son el Estado o la Administración los únicos titulares de tales intereses. Como expuso MEILÁn, esta identificación podría llevar a equiparar los intereses colectivos exclusivamente con los «gestionados directa o indirectamente por la Administración; o de otro modo, si son auténticos intereses colectivos, la actividad desplegada para conseguirlos calificará inequívocamente de administrativos a los entes que los desarrollen». Sin embargo, la realidad demuestra precisamente que este esquema ya no puede mantenerse porque «es un hecho comprobado la existencia de entes que, sin formar parte de la Administración pública, gestionan intereses públicos, pues como ha subrayado FoRSTHOFF, el Estado es función de la sociedad [...] se trata de poner el acento primariamente en los intereses colectivos y secundariamente en la Administración personificada. Aquéllos justifican la existencia de ésta y de su actividad» ${ }^{21}$.

La participación es hoy uno de los elementos constitutivos de la ciudadanía compleja - junto a los derechos y deberes y la pertenencia a una comunidad política - que atribuye «la oportunidad de contribuir a la vida pública de esa comunidad $»^{22}$. Se manifiesta en el ejercicio de los derechos civiles y políticos, así como en «la inserción orgánica o la intervención funcional de los ciudadanos en cuanto tales, con carácter voluntario y no profesional, en las Administraciones Públicas» ${ }^{23}$. Según NiETo, la participación en la toma de decisiones y en el ejercicio de funciones públicas se produce como una técnica para hacer posible «la realización de los intereses colectivos [...] Técnicas que han de responder a la sociedad en que nos encontramos (y no a la liberal) pero que no han de pretender imponer una forma social tecnocrática» ${ }^{24}$.

Entre las formas de participación se ha de destacar actualmente la denominada participación cooperativa constituida por una actividad estrictamente privada, que coopera voluntariamente en programas o actividades que la

\footnotetext{
${ }^{21}$ MeILÁn, J. L., «Veinticinco años de Ciencia administrativa en España», en Libro Homenaje al Profesor López Rodó, I, Madrid, BOE, 1971, pp. 75-76.

${ }^{22}$ García, S. y Lukes, S., Ciudadanía: justicia social, identidad y participación, Madrid, Siglo XXI, 1999, p. 1.

${ }^{23}$ Lavilla Rubira, J. J., «Participación», en Enciclopedia Jurídica Básica, III, Madrid, Civitas, 1995, p. 4773.

${ }^{24}$ NiETo, A., «La vocación del Derecho administrativo de nuestro tiempo», en Estudios de Derecho y Ciencia de la Administración, CEPC, Madrid, 2001,cit., p. 898.
} 
Administración patrocina o promueve. Lo pude hacer por medio de convenios y medidas de fomento, previo reconocimiento y calificación e inspección de la adecuada utilización ${ }^{25}$. Se utilizan distintas fórmulas para su formalización como los «contratos programa» (art. 91 LGP), los «acuerdos de colaboración» sobre los sistemas integrados de gestión de residuos de envases (Ley 11/1997, de 24 de abril), los «acuerdos voluntarios» sobre limpieza y restauración de suelos contaminados (Ley 10/1998, de 21 de abril), etcétera.

En este supuesto se incluyen las Fundaciones afectas a un «interés general» y no privado (arts. $34 \mathrm{CE}$ y $35.1^{\circ} \mathrm{CC}$ ) y las Asociaciones de «utilidad pública [...] dedicadas a fines asistenciales, educativos, culturales, deportivos o de cualesquiera otros fines que tiendan a promover el bien común» (art. 4 de la Ley de Asociaciones de 24 de diciembre de 1964, y Ley 1/2002, de 22 de marzo, reguladora del derecho de asociación). Se incluyen las «entidades sin fines lucrativos» beneficiadas por el régimen fiscal de la Ley 42/2002, de 23 de diciembre, que incluye las fundaciones, las asociaciones declaradas de utilidad pública, las organizaciones no gubernamentales para la cooperación al desarrollo (Ley 23/1998, de 7 de julio), las delegaciones de fundaciones extranjeras inscritas en el Registro de Fundaciones, las federaciones deportivas, los Comités Olímpico y Paralímpico y las federaciones y asociaciones de las entidades sin fines lucrativos anteriores. También se encuadran las asociaciones de defensa de los consumidores y usuarios que cumplan las condiciones de la Ley 26/1984, de 19 de julio.

Como supuesto de ejercicio de funciones administrativas, con mayor rango y contenido que las anteriores, se puede considerar las que realizan las entidades de base asociativa privada, que se encuadran en la denominada «Administración corporativa», tales como los Colegios profesionales (Art. $36 \mathrm{CE}$ ), las organizaciones profesionales representativas de intereses económicos (Art. $52 \mathrm{CE}$ ) y las Corporaciones de Derecho público que cumplen finalidades sociales como las Federaciones deportivas. También el ejercicio por los vecinos de acciones de defensa del patrimonio local (Art. 68 LRBRL).

BERMEJO señaló que la participación tiene las ventajas del acercamiento entre el poder público y la sociedad, contribuyendo a la flexibilidad de los aparatos burocráticos y a la transparencia de la acción administrativa ${ }^{26}$. Sin embargo, como todo, tiene desventajas por la generalización de las fórmulas de participación, como son la confusión de los intereses generales y los particulares de los próximos a los espacios de decisión, la demora de las

\footnotetext{
25 Ávila Orive, J. L., Los convenios de colaboración excluidos de la Ley de Contratos de las Administraciones Públicas, Madrid, Civitas, 2002. Bassols Coma, M., «Consideraciones sobre los convenios de colaboración de la Administración con los particulares para el fomento de actividades privadas de interés público», en $R A P, 84,1977$.
}

${ }^{26}$ SÁncheZ Morón, M., La participación..., cit., pp. 270 y ss. 
soluciones, los círculos caóticos, los mayores costes económicos, la dilución de las responsabilidades directas de la organización administrativa y la falta de responsabilización económica directa de los participantes cuando se produce a título colectivo ${ }^{27}$.

Hay un amplio campo de participación de los individuos, de la sociedad y de la economía con la Administración, ampliada por el Derecho comunitario, que «perfila una línea de relación entre los postulados de la participación democrática y los impulsos de desarrollo que implica el Estado de Derecho [...] orientados a la construcción de una estructura 'intermedia', que pondere los intereses y trascienda las posiciones jurídicas puramente individuales ${ }^{28}$.

La participación implica la «quiebra de la exclusividad de la detentación del poder real o efectivo por los órganos estatales titulares del poder formal político», por efecto de la importancia de las organizaciones sociopolíticas y del «carácter pluralista del orden sociopolítico, que comporta el papel central de la opinión pública fuertemente condicionada por los medios de comunicación social» ${ }^{29}$.

\section{EL EJERCICIO PRIVADO DE FUNCIONES PÚBLICAS. LA AUTORREGULACIÓN}

Históricamente el ejercicio de funciones públicas estaba limitado a la Administración pública y sólo se admitía la presencia de los particulares en su condición de concesionarios de servicios públicos o contratistas actuando por cuenta de aquella, pudiendo ejercer potestades de policía y dictar actos administrativos para proteger los bienes y la actividad. Actualmente, cuando se habla del ejercicio privado de funciones públicas se alude a «ciertas actividades que gozan de especial eficacia reconocida por el Derecho o que se ejercitan haciendo uso de potestades que, en principio, sólo corresponden a los poderes públicos ${ }^{30}$. El ordenamiento jurídico habilita para el ejercicio en nombre propio y bajo su responsabilidad de esas potestades.

El Consejo de Estado francés aceptó la gestión de servicios públicos por los particulares y la gestión de empresas de titularidad pública por medios privados, que dio lugar a la crisis definitiva del concepto material del servi-

\footnotetext{
27 Bermejo Vera, J., Derecho..., cit., pp. 43-44.

28 Schmidt-Assmann, E., La Teoría General..., cit., p. 118.

29 Parejo Alfonso, L., Estado social y Administración pública. Los postulados constitucionales de la reforma administrativa, Madrid, Civitas, 1983, p. 96.

${ }^{30}$ SÁinz Moreno, F., «Ejercicio privado de funciones públicas», en RAP, 100-102, 1983, p. 1781.
} 
cio público como caracterizador de la actividad administrativa ${ }^{31}$. En el arrêt Granits des Vosges (CE 31 juill. 1912, Rec. 909, concl. Blum) constató que en materia contractual los servicios públicos recurrían frecuentemente a los contratos de Derecho privado. El Tribunal de Conflictos en el arrêt Bac d'Eloka (TC 22 janv. 1921, Société Commerciale de Ouest Africain, Rec. 91, concl. Matter) entendió normal la gestión privada y régimen de Derecho privado de los servicios públicos. También asumió que personas privadas gestionasen un servicio público administrativo, reconociendo a las Cajas primarias de seguros sociales, personas jurídicas de Derecho privado, que se encargaran de la gestión de un servicio público de seguridad social (CE 13 mai 1938, Caisse Primaire Aide et Protection, Rec. 417, concl. Latournerie). En el arrêt Vezia de 20 de diciembre de 1935 y en el Bouguen de 2 de abril de 1943 se admitió la gestión privada y que personas no públicas pudieran dictar actos administrativos sin que mediara una concesión administrativa.

En estos casos el servicio público estaba en el fin perseguido pero no en el sujeto ni en los medios, lo que implicaba separarse de la concepción tradicional del servicio público basada en la titularidad administrativa de una actividad de interés general, en su gestión directa por la Administración o indirecta regulada y controlada por aquélla, sin aplicación de regla alguna del mercado ni de libre competencia por tenderse al monopolio administrativo ${ }^{32}$. Se justificaba en la naturaleza de los servicios prestados que eran parte del interés público gestionado exclusivamente por la Administración. Se ha explicado desde la técnica de la delegación a favor de los particulares y los «actos administrativos en sentido propio emanados de una persona jurídica formalmente privada encuentra de este modo completa explicación, en cuanto que dichas personas no actúan como simples sujetos privados [...] ni ejercitan poderes propios, sino que se presentan como órganos, delegados o agentes de la Administración en virtud de mecanismos de transferencia bien conocidos que transmiten poderes originariamente administrativos para el ejercicio de funciones previamente asumidas de modo formal y expreso por la Administración pública» ${ }^{33}$.

\footnotetext{
31 Rivero, J., «Le régime des entreprises nationalisés et l'évolution du Droit administratif», en Pages de doctrine, II, Paris, LGDJ, 1980, pp. 49 y ss. Baena del AlCázar, M., Régimen jurídico de la intervención administrativa en la economía, Madrid, Tecnos, 1966, pp. 103 y ss.; «Privatizaciones y misiones de servicio público», en El Derecho administrativo en el umbral..., cit., II, pp. 1881-1894. CASTells Arteche, J. M., «La actual coyuntura de la Administración prestadora de Servicios Públicos», en El Derecho administrativo en el umbral..., cit., pp. 1991-2010.

32 Ariño, G., Economía y Estado, Madrid, Pons, 2003, p. 338: «el monopolio de hecho se ha mantenido durante muchos años en la mayoría de los servicios públicos. En aquellos que exigían una infraestructura de red para su prestación (agua, gas, electricidad, telefonía y transmisión de datos o señales, ferrocarriles de todo tipo, trolebuses, etcétera) la justificación venía dada por la inconveniencia de duplicar las redes en estos sectores en los que se dan las condiciones económicas propias de un monopolio: disminución de coste con el aumento de demanda y aumento del coste con pluralidad de oferta».

${ }^{3}$ FERnÁndez Rodríguez, T. R., Derecho administrativo, sindicatos y autoadministración, Madrid, IEA, 1972, p. 22. SSTC 89/1989 y 179/1994. GARCÍA de EnTERRÍA, E. y FERnández RodríGUEZ, T.R., Curso..., cit., I, pp. 45-46.
} 
Así se desprende del artículo 20.b LJCA respecto a la presencia de la Administración en la relación jurídica y a la inclusión de «los particulares cuando obraren por delegación o como meros agentes o mandatarios de ella». También los concesionarios dictan actos administrativos cuando actúan como delegados de la Administración (art. 126.3 RSCL), las Asociaciones administradoras de concentraciones y agrupaciones forestales (art. $20 \mathrm{RM}$ ) y las Juntas de compensación (art. 126 LS 1976). Estos y otros supuestos demuestran que las normas del Derecho administrativo se extienden a otros sujetos y afectan al contenido del «estatuto de estos sujetos que, por razones comprensibles, no es homogéneo, pero [...] no cambia el concepto de Derecho administrativo ni, hablando propiamente, el de su ámbito de aplicación» ${ }^{34}$.

La ampliación de la actividad estatal en el Estado social supuso la necesidad de ampliar el aparato burocrático y contar con los administrados para poder atender las necesidades colectivas y hacer efectivos los fines de los entes públicos. Por otra parte, la participación en la toma de decisiones y en la gestión convierten a los «participantes» en auténticos gestores considerados «entidades colaboradoras» de la Administración, tengan o no ánimo de lucro. Ha alcanzado importante relieve la prestación de servicios sociales por la sociedad civil, llamado el Tercer Sector, integrado por instituciones de base privada con o sin ánimo de lucro, que comparten gestión y responsabilidad ${ }^{35}$. Así lo reconoció la exposición de motivos de la Ley 49/2002, de 23 de diciembre, de régimen fiscal de las entidades sin fines lucrativos y de los incentivos fiscales al mecenazgo, al adoptar medidas para incentivar «la colaboración particular en la consecución de fines de interés general, en atención y reconocimiento a la cada vez mayor presencia del sector privado en la tarea de proteger y promover actuaciones caracterizadas por la ausencia de ánimo de lucro, cuya única finalidad es de naturaleza general y pública».

El protagonismo asumido por las organizaciones sociales se sitúa, como se ha expuesto, dentro de la «participación cooperativa» y de su cada vez mayor presencia como manifestación de la sociedad civil y de la nueva gobernanza. Frente al carácter excepcional que representaba en épocas anteriores, hoy el ejercicio privado de funciones públicas forma parte del orden jurídico administrativo ${ }^{36}$. Se asume la existencia de cuerpos reguladores indepen-

\footnotetext{
${ }^{34}$ Rebollo Puig, M., «Derecho de la Administración pública y Derecho administrativo», en Rivista italiana di Diritto pubblico comunitario, 2, 2000, pp. 285-286.

35 JEREZ, A. (coord..), ¿Trabajo voluntario o participación? Elementos para una sociología del Tercer sector, Madrid, Tecnos, 1997.

36 Canals Ametller, D., El ejercicio por los particulares de funciones de autoridad. Control, inspección y certificación, Granada, Comares, 2003. Fernández FArreres, G., «La infraestructura para la calidad y la seguridad industrial y el fenómeno del ejercicio por particulares de funciones públicas de inspección y control», en RArAP, 13, 1998 y en El Derecho administrativo en el umbral..., cit., II, pp. 2575-2590. FERNÁNDEZ RAMOS, S., La actividad administrativa de inspección. El régimen jurídico general de la función inspectora, Granada, Comares, 2002. GonZÁlEZ-VARAS IBÁÑEZ, S., «El desarrollo de una idea de colaboración en el Derecho Administrativo, con el ejemplo de la seguridad privada y
} 
dientes de los poderes públicos, que supervisan actividades y sectores económicos importantes como servicios públicos, financieros y actividades tecnológicas de alto nivel, sin interferencias del poder político, administrativo o empresarial. Forman parte de lo que la OCDE ha denominado la «gobernanza normativa», que incluye, además, el análisis del impacto de la legislación (AIL), la consideración sistemática de las alternativas de regulación, la consulta pública y los mecanismos de mejora de la responsabilidad ${ }^{37}$.

El Derecho comunitario ha reforzado la tendencia al sustituir los procedimientos administrativos tradicionales de control por las certificaciones $\mathrm{u}$ homogenizaciones por parte de entidades privadas, de modo que «la privatización de funciones no conduce a una clara separación de las esferas de competencia pública y privada. [...] significa, más bien, que si antes el Estado tenía la responsabilidad de llevar a cabo directamente las tareas públicas, [...] ahora su misión es más bien supervisar la ejecución de esas tareas, lo que le obliga a acudir con más intensidad a la cooperación con los particulares. [...] desde el punto de vista del Derecho administrativo, los dos grandes sectores del ordenamiento, Derecho público y Derecho privado, se aproximan, puesto que, de un lado, las instituciones de uno y otro sector aparecen como alternativas que pueden cumplir una misma función, y el Derecho privado y el público en su conjunto como ordenamientos que se complementan y apoyan mutuamente en la función de disciplinar las distintas facetas de la acción administrativa». Ambos constituyen «ordenamientos de cobertura» como Derecho administrativo privado que atiende las necesidades de protección y delegación en las acciones en que se relacionan la Administración y las personas privadas ${ }^{38}$.

Forman parte de la llamada autoadministración, autorregulación y del Derecho reflexivo cuyo objetivo no sería la imposición autoritaria de mandatos o prohibiciones, sino la de incentivar y encauzar la actividad de los agentes sociales. Este nuevo orden jurídico promueve la intervención activa y responsable de los poderes y sistemas sociales. También está dando un nuevo

otros», en REDA, 94, 1997; «La responsabilidad administrativa en casos de colaboración de los particulares en el ejercicio de funciones administrativas», en REDA, 123, 2004, pp. 399-423. IzQUIERDO CARrasco, M., La seguridad privada: régimen jurídico-administrativo, Valladolid, Lex Nova, 2004. OJEDA MARín, A., «Entidades privadas colaboradoras de la Administración en el ámbito técnico», en Homenaje a José Antonio García-Trevijano Fos, Madrid, IEAL, 1982.

${ }^{37}$ OCDE, Políticas normativas en los países de la OCDE. Del intervencionismo a la gobernanza normativa, 4 de junio de 2003; La modernización del sector público: la modificación de las esrtrucgturas organizativas, octubre 2004.

38 Schmidt-Assmann, E., La Teoría General..., cit., pp. 303 y 304.

39 Prieur, M., Droit de l'environnement, Paris, Dalloz, 1991, p. 6. R. Martín Mateo, Tratado de Derecho Ambiental, I, Trivium, 1991, p. 94. Los estándares urbanísticos a incorporar en la ordenación urbana constituyen límites a la discrecionalidad para asegurar el uso racional del suelo y la satisfacción de las necesidades colectivas como «criterios mínimos de ordenación, no directamente aplicables, sino dirigidos a la Administración competente y de obligado seguimiento para ella» (STC 27-7-1988). 
significado a las normas técnicas que no se contraponen a las jurídicas, sino que se complementan en un proceso de clara tecnificación del derecho. Los estándares técnicos se han juridificado y las normas se han tecnificado, de modo que la regulación utiliza medios de acción tanto jurídicos como técnicos a los que dota de mayor eficacia y les permite adaptar la evolución técnica a las realidades sociales ${ }^{39}$.

La justificación de muchas de estas actividades está en la superación tecnológica, la rapidez de reacción y la falta de medios de la Administración, que dejan espacios de actividad sin regulación pública y conducen a la autorregulación y el autocontrol por medio de organizaciones, procedimientos y formulas concertadas en y con la sociedad ${ }^{40}$. También se incluyen actividades inspectoras, de control técnico, verificaciones medioambientales, de gestión de residuos, telecomunicaciones, biotecnología, energía, industria, medios de comunicación, etcétera, con la habilitación legal pertinente. Si «el saber tecnológico ha sobrepasado la capacidad de intervención de la Administración llegaremos inevitablemente a una de estas dos opciones: o rearmamos tecnológicamente a la Administración, o trasladamos a los particulares algunas de las funciones de control de la técnica» ${ }^{41}$.

La autorregulación tiene en la técnica su razón de $\operatorname{ser}^{42}$, de modo que la cláusula técnica enlaza este sistema con el jurídico, cuando este se remite a aquélla, de modo recepticio porque se «asumen como propios los resultados de la autorregulación. [...] cuando se produce una remisión nominada o precisa, que la identifique sin cuestión, a una concreta norma o declaración» ${ }^{43}$. Así se ha venido haciendo con la aplicación de la denominada «cláusula de progreso técnico de la ciencia» o la invocación de las «mejores técnicas disponibles», según la cual el concesionario ha de explotar y prestar el servicio de acuerdo con la técnica en cada momento vigente, según los últimos adelantos de la ciencia ${ }^{44}$. Se trata de una de las manifestaciones del principio de adaptación constante del servicio a las necesidades y exigencias de interés general, apoyada en el principio de transformación social del articulo $9 \mathrm{CE}$ y en la exigencia del servicio al interés general del artículo $103 \mathrm{CE}$,

\footnotetext{
${ }^{40}$ Malaret García, E., «Servicios públicos, funciones públicas, garantías de derechos de los ciudadanos: perennidad de las necesidades, transformación del contexto», en $R A P, 245,1998$, p. 72 y ss., se refiere al alcance material y técnico de la participación de los particulares en las funciones administrativas.

${ }^{41}$ Moles, R. J., Derecho y calidad, el régimen jurídico de la normalización técnica, Madrid, Ariel, 2001, p. 27.

${ }^{42}$ Esteve Pardo, J., Técnica, riesgo y Derecho, Barcelona, Ariel, 1999, p. 108: «mientras la Administración muestra sus limitaciones para dominar la complejidad técnica y el ordenamiento jurídico para regularla, se observa un proceso de racionalización, organización, sistematización y fortalecimiento [...] del sector de las entidades privadas de control técnico, por un lado, y también del régimen de configuración de normas técnicas, por otro».

${ }^{43}$ Esteve Pardo, J., Autorregulación. Génesis y efectos, Madrid, Aranzadi, 2002, p. 146.

${ }^{44}$ Guaita, A.: Derecho Administrativo. Aguas, Montes y Minas, Madrid, Civitas, 1986, p. 390. MEILÁN GIL, J. L.: La cláusula de progreso en los servicios públicos, Madrid, IEA, 1968.
} 
que el artículo 4.1.b) de la Ley 6/1997, de Organización y Funcionamiento de la Administración General del Estado concretó en el deber de asegurar la «continua mejora de los procedimientos, servicios, y prestaciones públicas» ${ }^{45}$. La incorporó la Carta Europea de los servicios públicos al exigir un «esfuerzo constante tendente a mejorar las respuestas a las demandas de los usuarios».

Se trata de una norma común en el Derecho Comunitario sobre el medio ambiente. El artículo 13 de la Directiva 75/439, de 16 de junio, sobre aceites usados, modificada por la 87/101, de 22 de diciembre de 1986, dispuso que «las autoridades competentes examinarán la evolución del estado de la tecnología y/o del medio ambiente con miras a la revisión, si fuera necesario, de la autorización concedida a una empresa de conformidad con la presente Directiva». El artículo 4.1. de la Directiva 84/360, de 28 de junio, en relación con las autorizaciones industriales que generan contaminación atmosférica, exige «asegurar que se han tomado todas las medidas adecuadas de prevención de la contaminación atmosférica, incluyendo la utilización de la mejor tecnología disponible, a condición de que la aplicación de dichas medidas no ocasione gastos excesivos» ${ }^{46}$. La resolución 94/C 48/01, del Consejo de 7 de febrero de 1994, sobre principios del servicio universal de las telecomunicaciones, dispuso en su aparato f) que «la noción de servicio universal debe evolucionar al ritmo del progreso técnico, del desarrollo del mercado y de los cambios en las necesidades de los usuarios». El Reglamento 761/2001 del Parlamento y el Consejo, de 19 de marzo de 2001, regula el sistema de ecogestión y auditoría medioambientales (EMAS) para «promover mejoras continuas de los resultados ambientales de la empresa mediante el establecimiento y aplicación por parte de las organizaciones de sistemas de gestión medioambiental», la evaluación, la difusión de la información y la implicación del personal ${ }^{47}$.

\footnotetext{
${ }^{45}$ Chevallier, J., «Politiques publiques et changement social», en RFDA, 115, 2005, pp. 383-390. Quermonne, J. L., Traité de science politique, 4, Paris, PUF, 1985, pp. 61 y ss.

${ }^{46}$ Se trata de la fórmula denominada BAT (Best Available Technology Not Excessive Costs). Su artículo 12 dispuso: «Los Estados miembros seguirán la evolución de la mejor tecnología disponible y de la situación del medio ambiente. A la vista de dicho examen, impondrán, si es necesario, unas condiciones adecuadas a las instalaciones autorizadas de conformidad con la presente Directiva, teniendo en cuenta, por un lado, dicha evolución y, por otro, la conveniencia de que no ocasionen gastos excesivos a las instalaciones de que se trate, en atención, en particular, a la situación económica de las empresas pertenecientes a la categoría considerada». El artículo 13 de la misma Directiva 84/360 se refiere a las instalaciones autorizadas y en funcionamiento a las que también se deberán incorporar las innovaciones tecnológicas: «A la vista del examen de la evolución de la mejor tecnología disponible y de la situación del medio ambiente, los Estados miembros aplicarán políticas y estrategias, incluyendo unas medidas adecuadas para adaptar progresivamente las instalaciones existentes pertenecientes a las categorías que figuran en el Anexo I a la mejor tecnología disponible, teniendo en cuenta en particular: - las características técnicas de la instalación; - el índice de utilización y el período de vida residual de la instalación; - la naturaleza y el volumen de las instalaciones contaminantes de la instalación; - la conveniencia de que no ocasionen gastos excesivos a las instalaciones de que se trate, en atención en particular a la situación económica de las empresas pertenecientes a la categoría considerada».
}

${ }^{47}$ El Reglamento CEE 1836/93, de 29 de junio de 1993, modificado por el Reglamento 761/2001, del Parlamento y del Consejo, de 19 de marzo de 2001, permitió a las empresas del sector industrial adhe- 
La presencia de agentes sociales de carácter privado en relación con el contenido técnico es una realidad acreditada y reconocida. Así viene sucediendo, como lo recogió la exposición de motivos de la Ley 21/1992, de 16 de julio, de industria, al constatar que las funciones de seguridad industrial, como la normalización, homologación y certificación, por su incremento y complejidad se han desarrollado por entidades colaboradoras de las Administraciones públicas y laboratorios privados ${ }^{48}$.

El RD 2200/1995, de 28 de diciembre, complementó al RD 2584/1981, de 18 de septiembre y aprobó el Reglamento de la Infraestructura para la Calidad y la Seguridad Industrial. Creó un Registro de Establecimientos Industriales en el que se inscriben las entidades de acreditación, «privadas sin ánimo de lucro, que se constituyen con la finalidad de acreditar o reconocer formalmente, en el ámbito estatal y a través de un sistema conforme a normas internacionales, la competencia técnica de una entidad para certificar, inspeccionar o auditar la calidad o de un laboratorio de ensayo o de un laboratorio de calibración, que operen tanto en un ámbito voluntario de la calidad como en el ámbito obligatorio de la seguridad industrial, o de una persona o entidad en el ámbito de la verificación medioambiental» (art. 14) ${ }^{49}$.

En materia medioambiental, el RD 85/1996, de 26 de enero, en desarrollo de la Ley 21/1992, autoriza al Estado y a las Comunidades Autónomas para designar las entidades de acreditación para realizar «verificaciones medioambientales independientes y a supervisar sus actividades $\aleph^{50}$, designando como tal a la asociación Entidad Nacional de Acreditación (ENAC), entidad privada, independiente y sin ánimo de lucro, que coordina un sistema de acreditación conforme a criterios y normas internacionales para Laboratorios de Ensayo y Calibración (UNE-EN ISO/IEC 17025), Laboratorios Clínicos (UNEEN ISO 15189), Entidades de Inspección (UNE-EN ISO 17020), Entidades de Certificación de Productos (UNE-EN 45011-ISO/IEC Guide 65), Entida-

\footnotetext{
rirse con carácter voluntario a un sistema comunitario de gestión y auditoría medioambientales para la «valuación y mejora de los resultados de las actividades industriales en relación con el medio ambiente y la facilitación de la correspondiente información al público» (art. 1). Su artículo 4 previó que la auditoría interna fuera realizada por los auditores de la empresa o por «personas u organismos externos que actúen por cuenta de la empresa». Contempla la existencia de entidades de acreditación registradas (arts. 6-11) y en el Anexo III los requisitos para la acreditación y las funciones de los verificadores medioambientales. Lozano Cutanda, B., Derecho Ambiental Administrativo, Madrid, Dykinson, pp. 301-316. Schmidt-Assmann, E., La Teoría General..., cit., p. 370.

48 CArrillo Donaire, J.A., El derecho de la seguridad y de la calidad industrial, Madrid/Barcelona, IGO/M. Pons, 2000. IzQuierdo Carrasco, M., La seguridad de los productos industriales, Madrid, 2000. Rodríguez-CAmpos, S., Calidad industrial e intervención administrativa, Barcelona, 2002.

49 Redactado conforme al RD 411/1997, de 21 de marzo, que modificó el RD 2200/1995, de 28 de diciembre. La competencia técnica es uno de los fundamentos que justifican la existencia de las Administraciones Independientes y reguladoras: BETANCOR RodríGUEZ, A., Las Administraciones independientes, Madrid, Tecnos, 1994, pp. 212-213.

50 TARRÉs VIVES, M., «Los sujetos privados en la gestión y auditoría medioambiental comunitaria. Su desarrollo en la Umweltauditgesetz alemana», RAP, 145, 1998.
} 
des de Certificación de Sistemas de Calidad (UNE-EN 45012-ISO/IEC Guide 62), Entidades de Certificación de Sistemas de Gestión Medioambiental (UNEEN 45012-ISO/IEC Guide 66), Entidades de Certificación de Personas (UNEEN ISO/IEC 17024), Proveedores de Programas de Intercomparación (UNE 66543-1 IN), Verificadores Medioambientales del sistema comunitario de ecogestión y ecoauditoría (Reglamento CE 761/2001) y Buenas Prácticas de Laboratorio para entidades que realizan estudios de productos fitosanitarios (RD 1369/2000). Son sus socios las entidades y laboratorios acreditados que lo soliciten, las personas físicas o jurídicas con intereses técnicos o económicos, las Administraciones y entes públicos que concierten convenios o acuerdos de colaboración y los representantes de las Administraciones públicas que designan el Consejo de Coordinación de la Seguridad Industrial como socios natos.

Existen otros muchos supuestos, algunos muy notorios por su importante presencia, como es la inspección técnica de vehículos de transporte por carretera (ITV) establecida por la Directiva 96/96/CE del Consejo, de 20 de diciembre de 1996, traspuesta por los RRDD 2344/1985, 2042/1994, de 14 de octubre, y 7/2000, de 23 de junio. La inspección puede realizarse por las Comunidades Autónomas o Administración competente, directamente, por sociedades de economía mixta en cuyo capital participen o por particulares ${ }^{51}$.

La normalización industrial está regulada en la Ley 1992/1985, de 1 de agosto, y el RD 1614/1985, de 1 de agosto. El artículo 8 de la Ley 21/1992, de 16 de julio, recoge los conceptos que utiliza la Ley sobre la seguridad y calidad industriales. La normalización es «la actividad por la que se unifican criterios respecto a determinadas materias y se posibilita la utilización de un lenguaje común en un campo de actividad concreto» ${ }^{52}$. Existen dos tipos de normas: las técnicas en sentido estricto y el reglamento. Las primeras contienen «la especificación técnica de aplicación repetitiva o continuada cuya observancia no es obligatoria, establecida con participación de todas las partes interesadas, que aprueba un Organismo reconocido, en el ámbito nacional o internacional, por su actividad normativa». El reglamento técnico incluye «la especificación técnica relativa a productos, procesos o instalaciones industriales, establecida con carácter obligatorio a través de una disposición, para su fabricación, comercialización o utilización». El acto de

\footnotetext{
${ }^{51}$ Arana García, E., «Naturaleza jurídica de la actividad de inspección técnica de vehículos», en RVAP, 54, 1999.

${ }^{52}$ Boy, L., «La valeur juridique de la normalisation», en Clam, J. y MARTin, G., Les transformations de la régulation juridique, Paris, LGDJ, 1998, p. 183. Álvarez GARCÍA, V., «Introducción a los problemas jurídicos de la normalización industrial: normalización industrial y sistemas de fuentes», en $R A P 147,1998$, p. 309, define la normalización, versión española de la estandarización, como «el proceso dirigido a la elaboración o producción de unos elementos de referencia comunes [...] destinados a la ordenación uniforme de los diferentes comportamientos o actividades humanas que se presentan de manera repetitiva en las relaciones sociales. En tanto que elementos de referencia, obligatorios o no, las normas provocan la simplificación o la reducción de la variedad de los comportamientos o actividades humanas que, como regla general, tenderán a acercarse al marco referencial previsto en las normas».
} 
«homologación» es la «certificación por parte de una Administración Pública de que el prototipo de un producto cumple los requisitos técnicos reglamentarios». La acreditación es «una actividad administrativa reglada, y de mera comprobación de requisitos. Viene a ser, por ello, una prueba anticipada, creada por la Administración para facilitar a la persona su participación en el tráfico jurídico; o para permitirle el acceso a determinadas actividades $»^{53}$.

Conforme a la definición del artículo 8, los organismos de control son «entidades que realizan en el ámbito reglamentario, en materia de seguridad industrial, actividades de certificación, ensayo, inspección o auditoría». El artículo 15 establece su régimen, como «Entidades públicas o privadas, con personalidad jurídica, que habrán de disponer de los medios materiales y humanos, así como de la solvencia técnica y financiera e imparcialidad necesarias para realizar su cometido, debiendo cumplir las disposiciones técnicas que se dicten con carácter estatal a fin de su reconocimiento en el ámbito de la Comunidad Europea». Su autorización corresponde a la Administración competente en materia de industria del territorio donde inicien su actividad o radiquen sus instalaciones. El régimen de su funcionamiento lo establece el artículo 16, mientras que el artículo 17 se refiere a las entidades de acreditación como instituciones sin ánimo de lucro para verificar en el ámbito estatal el cumplimiento de las condiciones y requisitos técnicos exigidos para el funcionamiento de los Organismos de Control.

El valor jurídico del régimen es el derivado de la adhesión voluntaria a una norma no obligatoria, pero cuya aceptación y calificación atribuye al producto, proceso o servicio un marchamo de calidad en el ámbito correspondiente. Sólo es obligatoria si una disposición legislativa se remite a la norma industrial, que eleva la autorregulación para darle valor administrativo, lo que no excluye que la Administración pueda asumir la valoración realizada por el organismo regulador ${ }^{54}$.

La entidad más acreditada es la International Organization for Standardization (ISO), cuyas «Normas ISO» se refieren a los distintos campos de la actividad industrial y ambiental. En Europa existe el Comité Europeo de Normalización (CEN) y en España la Asociación Española de Normalización

\footnotetext{
${ }^{53}$ Morell Ocaña, L., Curso de Derecho Administrativo, II, Pamplona, Aranzadi, 1999, p. 38. Tarrés VIVES, M, «Las nuevas referencias en el Derecho industrial: acreditación y normalización», en Autonomies, 26, 2000, define la acreditación como «el reconocimiento formal de la competencia técnica de una entidad para certificar, inspeccionar o auditar la calidad, o un laboratorio de ensayo o de calibración industrial»

54 Álvarez García, V., «Introducción a los problemas jurídicos de la normalización industrial: normalización industrial y sistema de fuentes», en $R A P, 147,1998$; La normalización industrial, Valencia, Tirant lo Blanch, 1999; «La protección del medio ambiente mediante las técnicas de la normalización industrial y de la certificación», en REDA, 105, 2000. FernÁndez FARRERES, G., «Normalización y homologación de productos industriales», en MARTíN-Retortillo, S., Derecho administrativo económico, II, Madrid, La Ley, 1991. PADrós ReIG, C., Actividad industrial y entidades colaboradoras, Madrid, Tecnos, 2001.
} 
y Certificación (AENOR). Esta última fue calificada como organismo acreditado para la normalización y certificación industrial en todos los sectores industriales y de servicios por la OM del Ministerio de Industria y Energía de 26 de febrero de 1986 y por los RRDD 1614/1985 y 2200/1995, de 28 de diciembre, Reglamento de la Infraestructura para la Calidad y la Seguridad Industrial, participando en la elaboración de las Normas UNE ${ }^{55}$.

El significado de la autorregulación y Derecho reflexivo de estas convenciones entre partes, ajenas a las organizaciones públicas, está recogido en la Guía ISO 2 de 1986, que definió la Norma ISO como la «especificación técnica u otro documento, accesible al público, establecida con la cooperación y el consenso o la aprobación general de todas las partes interesadas, basada en los resultados conjuntos de la ciencia, de la tecnología y de la experiencia, que tiene por objetivo el beneficio óptimo de la comunidad en su conjunto y que ha sido aprobada por un organismo cualificado a nivel nacional, regional o internacional». La autorregulación ha progresado de manera considerable en materia medioambiental, como lo acredita la existencia de una Norma ISO 14001, con las condiciones que han de cumplir las organizaciones que traten de conseguir la certificación.

El Libro Blanco sobre los Sistema de Autorregulación, los Sellos y las Marcas de Confianza en Mercados Digitales y Códigos de Buenas Prácticas para el Comercio Electrónico constata el contenido de «los sistemas de autorregulación [que] son impulsados por asociaciones sectoriales con objeto de resolver cuestiones comunes al sector a través de una solución surgida desde la comunidad empresarial». Destaca como ventajas de los sistemas de autorregulación la implicación empresarial en su elaboración y cumplimiento, así como su poco coste económico. Sus desventajas pueden ser la falta de credibilidad de los consumidores, su escaso contenido normativo o la ausencia de auditoría por entidades independientes del sector. Respecto a los Códigos de buenas prácticas o guías, valora que «imponen pautas, no mandatos, de contenido flexible y que son elaborados por consenso entre todas las partes interesadas». Son sus características intrínsecas las que condicionan su uso voluntario total o parcial o su combinación con otros, que pueden ser certificados por terceros independientes para obtener la licencia de uso de una marca. Las ventajas de los códigos son la participación en su elaboración, la independencia y credibilidad de los terceros que intervengan, el contenido flexible de sus normas, su constante revisión y mejora y la transparencia de sus requisitos y de los procedimientos de certificación. La autorregulación sectorial en el ámbito local la considera un estadio intermedio entre los ámbitos nacional e internacional capaz de suscitar colaboración para el desarrollo de proyectos de calidad comunes con otros sectores, aunque tiene la desventaja

\footnotetext{
${ }^{55}$ La Asociación Española para la Calidad (AEC) es una entidad privada sin ánimo de lucro para el fomento y apoyo a la cultura de la calidad con el fin de aumentar la competitividad de las empresas, integrada en la European Organization for Quality (EOQ).
} 
del reducido ámbito y contenido por la necesidad de lograr un mayor consenso ${ }^{56}$.

Todo esto, y otros muchos supuestos, acreditan que, según expuso EsTEVE, «la imagen de una sociedad verticalmente estructurada y envuelta en unas normas o un ordenamiento común con presencia capilar en toda ella no se correspondería así con la realidad actual ${ }^{57}$. Ahora bien, el valor normativo externo y erga omnes sólo se produce si el ordenamiento jurídico lo permite, se remite o asume, como hemos visto en casos concretos, porque el artículo 103.2 CE establece una reserva de Ley sobre las decisiones de la organización y del poder administrativo. Así lo confirmó el artículo 15 de la Ley 30/1992 al regular las encomiendas de gestión a personas o entes de Derecho privado, a las que no pueden encomendarse «actividades que, según la legislación vigente, hayan de realizarse con sujeción al Derecho administrativo». Régimen que es aplicable, también, a la gestión privada de servicios públicos y a la utilización del Derecho privado por la Administración.

\section{LA GESTIÓN PRIVADA DE SERVICIOS PÚBLICOS EN EL MODELO COMUNITARIO}

Una de las características del modelo económico de influencia neoliberal y de la globalización es la pérdida del papel de la Administración en el ejercicio de las funciones públicas que representan la autorregulación y el derecho convencional o reflexivo, así como la puesta en manos privadas de la gestión de servicios públicos. La evolución en este campo está directamente relacionada con la incorporación a la Unión Europea, porque «los procesos privatizadores en los sectores de las telecomunicaciones, la energía y los transportes constituyen un ejemplo de innovaciones en los Derechos de los Estados miembros que difícilmente hubieran podido llevarse a cabo sin la presión originada desde el Derecho comunitario» ${ }^{58}$. La integración europea se fundamenta, inicialmente, en un fin económico por el establecimiento de la libre concurrencia para dar iguales posibilidades a todos los agentes económicos. Como expone RodríGueZ-Arana, «el concepto de servicio público deudor de una concreta y peculiar manera ideológica de entender las relaciones Estado-sociedad, pierde su sentido jurídico-administrativo al desvanecerse el marco general que le servía de apoyo. Se reduce notablemente en su configuración por cuanto ahora lo normal y ordinario es la realización de deter-

\footnotetext{
${ }^{56}$ Libro Blanco sobre los Sistema de Autorregulación, los Sellos y las Marcas de Confianza en Mercados Digitales y Códigos de Buenas Prácticas para el Comercio Electrónico, Madrid, AENOR, 2002, pp. 75, 77-78, 81 y 92 .

57 Esteve Pardo, J., Autorregulación..., cit., p. 32.

58 Schmidt-AsSmann «El Derecho administrativo..., cit., p. 25. FAINÉ, I. y FornsEA, R., Gestión privada del servicio público, Barcelona, Real Academia de ciencias Económicas y Financieras, 2000.
} 
minadas actividades de relevancia pública en régimen de libertad, en régimen de competencia. Por ello, insisto, en un nuevo marco aparecen nuevos conceptos que ponen en cuestión la versión clásica de la noción de servicio publico» ${ }^{59}$.

El servicio público fue invocado por el artículo 77 del Tratado de Roma respecto a los transportes terrestres que autoriza «las ayudas que correspondan al reembolso de determinadas obligaciones inherentes a la noción de servicio público», ampliable a otros servicios básicos. Por el artículo 90. 1 para las empresas públicas y las que concedan derechos especiales o exclusivos sin eximirlas de las normas de los artículos 7 y 85; en el apartado 2 respecto a las empresas encargadas de prestar un «servicio de interés económico general o que tengan el carácter de monopolio fiscal, que estarán sometidas al Tratado, en particular a las normas de la competencia si no impide el cumplimiento de su misión específica ${ }^{60}$. La exclusividad que había sido característica del servicio público queda limitada a misiones específicas que la hagan indispensable bajo el control de la Comisión (art. 90.3) ${ }^{61}$.

Tradicionalmente se han atribuido al servicio público las siguientes características: se trata de una actividad estatal, asumida en su titularidad por el Estado, destinada al público y a la utilidad de los ciudadanos, que es de reconocida necesidad e indispensable para la vida social, cuyo ejercicio no supone el ejercicio de poderes soberanos o de autoridad ${ }^{62}$. Es la actividad de interés general la que califica al servicio público, no su organización, aunque no todas las actividades de interés general son tales servicios, sino las que reciban este carácter por su creación, organización y funcionamiento por una decisión de los poderes públicos, que les otorga la calificación de «servicio público», que las diferencia de otras actividades reglamentadas por ser de interés público, como son los servicios públicos virtuales o impropios ${ }^{63}$. No implica que deban ser desempeñados directamente por aquellos, sino que pueden ser prestados de modo indirecto por agentes privados en formas de gestión externalizada.

Entre los fines de los servicios públicos se encuentran la lucha contra la exclusión de las personas discapacitadas, en situaciones críticas o con recursos

\footnotetext{
${ }^{59}$ Rodríguez-Arana, J., «Servicio público y Derecho comunitario europeo», en Revista catalana de dret públic, 31, 2005, p. 378.

${ }^{60}$ Las STJCE de 17 de febrero de 1993, Poncet y Pistrel/AGF y Cancava, C-160/91, y de 23 de abril de 1998, Col/Union de caisses de maladie, C-159/96, admiten la creación de monopolios de servicios públicos de naturaleza no económica, aunque en el ejercicio de sus fines deben respetar las grandes libertades establecidas por el Tratado.

${ }^{61}$ El Reglamento CEE 3577/92, de 7 de diciembre, sobre transporte marítimo, autorizó a los Estados miembros a «celebrar contratos de servicio público o imponer obligaciones de servicio público a las compañías marítimas que efectúen servicios regulares con destino u origen en islas, como condición para prestación de servicios de cabotaje».
}

${ }^{62}$ ARIÑo, G., Economía..., cit., p. 294. 
insuficientes, la búsqueda de la cohesión social y el sentimiento de pertenencia a una comunidad de un determinado ámbito territorial, o la de favorecer una utilización eficaz y equilibrada del territorio y de los recursos comunes ${ }^{64}$. Constituyen actividades que no atienden el mercado ni la competencia y deben ser satisfechas por razones de interés general. Se pueden calificar, en el sentido histórico, de «servicios esenciales» 0 «servicios esenciales universales», en cuanto se trata de «actividades industriales o mercantiles de las que derivan prestaciones vitales o necesarias para la vida de una comunidad» (STC 26/ 1981, de 17 de julio) ${ }^{65}$. Según la doctrina del Tribunal de Justicia de la Comunidad una actividad es de interés general cuando corresponde a una misión específica y utiliza varios criterios como que el beneficiario en conjunto de modo indeterminado, que se confíe de modo expreso por un acto jurídico al organismo afectado y que conste la voluntad de la autoridad pública de que la actividad sea gestionada como servicio público ${ }^{66}$.

El concepto de cohesión social y territorial está incorporado en el artículo 16 del Tratado de la Unión referido a los «servicios de interés económico general», así como en el artículo 36 de la Carta de los derechos fundamentales que afirma el derecho de los ciudadanos al acceso a dichos servicios con el mismo fin (arts. 3.1.k, 158-162 TCE).

La Comisión europea calificó de «realidad proteica» las actividades de servicio público que son «un elemento clave del modelo europeo de sociedad ${ }^{67}$ y parte indispensable de ese modelo ${ }^{68}$. La Comunicación de la Comisión de 20 de septiembre de 2000 constata los principios de libertad de las autoridades públicas de los Estados miembros para la creación, la organización y la financiación de los servicios públicos. Además, son «los primeros responsables de la definición de lo que consideren como servicios de interés económico general» (punto 22), la Comisión «no se ocupa de saber si las empresas responsables de la prestación de servicios de interés económico general deberán ser públicos o privados», y la neutralidad está garantizada por el artículo 295 (punto 21). En ese mismo precepto se fundamenta la libertad y discrecionalidad de la persona pública para elegir el modo de organización del servicio público para su gestión directa o indirecta, interna o

\footnotetext{
63 Ariño, G., Economía..., cit., pp. 306 y ss.

${ }^{64}$ Henry, C., Concurrence et services publics dans l'Union européenne, Paris, PUF, 1997, pp. 6-8.

65 AriÑo, G. y De la CuÉtara, J. M., El nuevo..., cit., p. 152: «tan sólo las prestaciones básicas son exigibles por medios de Derecho público [...] todo lo demás debe negociarse y exigirse mediante fórmulas comerciales comunes».

${ }^{66}$ SSTJCE de 21 de marzo de 1974, 127/73, BRT/SABAM, 11 de abril de 1989, 66/86, Ahmed Saeed Flugreisen e.a., 23 de octubre de 1997, C-159/92, Comisión c. Francia.

${ }^{67}$ Comunicación de la Comisión de 20 de septiembre de 2000, «Los servicios de interés general en Europa», COM, 2000, 580 final, DOCE, 19 de enero de 2001, C 17, p. 4.

${ }^{68}$ Les valeurs européennes à l'ère de la mondialisation, COM, 2005, 525 final, 20 de octobre de 2005, p. 5. Auby, J.-F., Les services publics en Europe, Paris, PUF, 1998.
} 
externa, aunque existen servicios que sólo se pueden prestar directamente por medios público como la policía, según disponga el derecho interno.

El Libro Verde de la Comisión de 21 de mayo de 2003, sobre los servicios de interés general, constató su complejidad en la Unión Europea, que comprendía elementos muy diferentes agrupadas en las siguientes categorías: diversidad de actividades como las grandes industrias de redes (energía, servicios postales, transportes y telecomunicaciones), salud, educación y servicios sociales; diversidad de los niveles territoriales de prestación (locales, nacionales, europeos e, incluso, mundiales), y diversidad organizativa en función de las características históricas de su régimen y de la propia actividad. El Libro verde y la Comunicación de la Comisión al Parlamento Europeo, al Consejo, al Comité Económico y Social y al Comité de las Regiones en relación con el Libro Blanco sobre los servicios de interés general, recogió los conceptos de aquel en las siguientes categorías:

a) Servicios de interés general.

Concepto más amplio y derivado del de servicios de interés económico general, que «abarca los servicios, sometidos o no a la disciplina de mercado, que las autoridades públicas consideran de interés general y están sometidos a obligaciones específicas de servicio público».

b) Servicios de interés económico general.

Los servicios interés económico general (arts. 16 y 86.2 del Tratado) designan los «servicios de naturaleza económica a los que los Estados miembros o la Comunidad imponen obligaciones específicas de servicio público en virtud de un criterio de interés general. Por consiguiente, entran dentro de este concepto ciertos servicios prestados por las grandes industrias de redes, como el transporte, los servicios postales, la energía y las comunicaciones. Sin embargo, esta expresión abarca igualmente otras actividades económicas sometidas también a obligaciones de servicio público».

c) Servicio público.

Término más ambiguo que los anteriores y con diversos significados, que confunde «servicio público» con «sector público» por lo que se rechaza en el documento. "Con esta expresión se alude a veces al hecho de que un determinado servicio se ofrece al público en general, mientras que otras veces lo que se quiere resaltar es que se ha asignado a un servicio una misión específica de interés público o se hace referencia al régimen de propiedad o al estatuto de la entidad que presta el servicio».

d) Obligaciones de servicio público.

Alude a las «obligaciones específicas impuestas por los poderes públicos al proveedor del servicio con el fin de garantizar la consecución de ciertos 
objetivos de interés público, por ejemplo en materia de transporte aéreo, ferroviario y por carretera, o en el sector de la energía. Estas obligaciones pueden aplicarse a escala regional, nacional o comunitaria».

e) Empresa pública.

Se utiliza «para definir el régimen de propiedad del proveedor de un servicio. El Tratado prevé a este respecto una estricta neutralidad ${ }^{69}$. Con arreglo al Derecho comunitario, es irrelevante que los proveedores de servicios de interés general sean públicos o privados; todos están sujetos a los mismos derecho y obligaciones».

Frente al modelo histórico del servicio público continental, la Comunidad les exige actuar en las mismas condiciones de concurrencia que los privados, prohíbe las prácticas contrarias y sostiene la necesidad de eliminar la posición dominante ${ }^{70}$ y los conflictos e intereses, potenciando la diferenciación entra la actividad reguladora y la de gestión o explotación para garantizar la libre competencia (SSTJCE 3 de julio de 1991, AKZO c. Comisión, 19 de marzo de 1991, Francia vs. Comisión, C-202/88 y 17 de noviembre de 1992, España vs. Comisión). Para ello se está produciendo «la ruptura de la concepción orgánica del servicio público (de modo que es más habitual su gestión por privados), y el sometimiento de todos los servicios públicos económicos, con carácter general, al Derecho de la competencia» ${ }^{71}$.

Implica la construcción de un modelo de servicio público comunitario, que sustituye el clásico del servicio público de origen francés ${ }^{72}$ por otro con im-

\footnotetext{
${ }^{69}$ El principio de neutralidad está recogido en el artículo 295 del Tratado que «no prejuzga en modo alguno el régimen de la propiedad en los Estados miembros». En su virtud se trata de igual modo a los operadores público o privados en la aplicación de los principios que rigen la concurrencia. Está recogido en las STPI de 27 de febrero de 1997, T-106/95, FFSA (La poste) y STJCE de 25 de marzo de 1998, C-174/97.
}

${ }^{70}$ Para la STJCE de 14 de febrero de 1978, As. 27/66, United Brands c. Comisión, consideró comportamientos abusivos de las empresas por su posición dominante los que «influyen en la estructura del mercado en los que, como consecuencia de la presencia de la empresa en posición dominante, el grado de concurrencia está ya debilitado y que tienen por efecto obstaculizar [...] el mantenimiento del grado de concurrencia existente en el mercado o a desarrollar la concurrencia». La concesión de derechos exclusivos exige «que la misión particular que se le ha encomendado no pueda asegurarse más que por la concesión de tales derechos» (STJCE de 23 de octubre de 1997, C-159/94, Comisión c. Francia); demostrar su carácter necesario y proporcionado (STJCE de 19 de mayo de 1993, C-320/91, Corbeau); «la duración de la concesión debe fijarse de manera que no restrinja la libre concurrencia más allá de lo que es necesario para asegurar la amortización de las inversiones y una remuneración razonable de los capitales invertidos» (STJCE de 17 de mayo de 1984, 15/83, Denkavit Nederland); no debe conducir a una situación que pueda producir el abuso dela posición dominante (STJCE de 21 de abril de 1991, C-41/90, Höner y Elener c. Macrotron), ni desconocer las reglas generales del tratado como igualdad, transparencia y reconocimiento muto (STJCE de 28 de marzo de 1996, Procédure pénale contra Guiot).

${ }^{71}$ Muñoz Machado, S., Servicio..., cit., p. 223. Díez Picazo, L. M:, «La idea de servicios de interés económico general», en REDA, 2, 2002.

${ }^{72}$ Se fundamentó en el preámbulo de la Constitución de 1946, que forma parte del bloque de la constitucionalidad, en el que se afirma: «todo bien, toda empresa, cuya explotación tenga o adquiera el ca- 
portantes elementos de carácter norteamericano, en una «convergencia en la forma de intervención a la que se sujetan los servicios esenciales en Europa y Estados Unidos. Pues en ambos ámbitos se ha manifestado una tendencia a sustituir los métodos tradicionales de intervención, bien sea regulación o servicio público, por el recurso a la competencia ${ }^{73}$. La terminología debe ser también diferente porque mientras en el régimen norteamericano es correcto hablar de desregulación, en Europa lo es de liberalización ${ }^{74}$. A esta aproximación contribuye la plena incorporación de los llamados «servicios públicos virtuales o impropios» por no estar atribuidos a la Administración y gestionarse por entidades privadas, como es el caso de la educación ${ }^{75}$.

Este proceso conduce a que los servicios públicos no se presten directamente por la Administración, sino que, bajo su control y en régimen de libre concurrencia, lo hagan entidades privadas, que es conocido como la regulación·vinculada «al proceso de liberalización de la economía [...] por el que entendemos la apertura de sectores de la actividad económica antes reservados al sector público (reserva jurídica, que podía ir o no acompañada de la reserva de gestión) a la libre iniciativa económica», al que también suele aplicarse el término privatización, distinta de la forma de actuar con fórmula privada. Se diferencia, por tanto, la regulación de la prestación como agente económico «desde una posición neutral en relación a los fines que se consigan dentro del campo de juego, de la actividad consistente en imponer a través de las reglas de conducta unos determinados fines» ${ }^{76}$.

El nuevo régimen se debate entre los objetivos de dos polos opuestos: «lograr instaurar un sistema más eficaz y competitivo, que permita, además,

rácter de un servicio público nacional o de un monopolio de hecho debe ser propiedad de la colectividad». Su régimen jurídico fue establecido por el Consejo de Estado sobre los principios de igualdad, continuidad y adaptabilidad; su concepción económica se basa en el keinesianismo, las teorías de los bienes públicos y el monopolio natural.

${ }^{73}$ Sendín García, M. A., Regulación y servicios públicos, Granada, Comares, 2003, p. 16: «en el Derecho americano lo normal es que la prestación de los servicios públicos esenciales sea, salvo excepciones, llevada a cabo por empresas privadas, que persiguen, como cualquier otra empresa, una rentabilidad económica, pero que, en cuanto prestan un servicio público, están sometidas a una regulación pública minuciosa, supervisada por el control judicial». VAndamme, J. y VAn Der MensbrugGhe (dir.), La régulation des services publics en Europe, Bruselas, Aspe, 1998.

74 Sendín García, M. A., Regulación..., cit., p. 19.

${ }^{75}$ Gómez-Ferrer, R., «El régimen general de los centros privados de enseñanza», en $R A P, 70,1973$, pp. 7 y ss. CAstells Arteche, J. M., «La actual coyuntura de la Administración prestadora de servicios públicos», en Sosa WAGner, F. (dir.), El Derecho Administrativo en el umbral del siglo XXI. Homenaje al Prof. Dr. D. Ramón Martín Mateo, III, Valencia, Tirant lo Blanch, 2000, pp. 1991 y ss. LóPeZ Pellicer, J. A., «El servicio público y la habilitación de actividades prestacionales de interés general a particulares», ibidem pp. 2025 y ss. PARADA, R., «Los servicios públicos en España», en Estudios en homenaje al profesor Allar R. Brewer Carías, III, Madrid, Civitas, 2003, pp. 1843 y ss. BéLoRGEY, J. M., «Service public, services publics: déclin ou renouveau», en Études et Documents du Conseil d'État, 46, 1995, pp. 14 y ss. Número monográfico de AJDA, junio 1997.

${ }^{76}$ Tornos MAS, J., Las autoridades reguladoras de lo audiovisual, Madrid, M. Pons, 1999, p. 53; «La actividad de regulación», en El Derecho administrativo en el umbral..., cit., I, pp. 1329-1343. 
la creación de un auténtico mercado europeo, en que empresarios públicos y privados compitan en condiciones de igualdad» $\mathrm{y}$ «mantener el alto grado de protección social que ha ofrecido nuestro sistema tradicional, o incluso mejorarlo». Todo esto por medio de un sistema «que permita mantener la consecución de finalidades tradicionales del servicio público en un contexto liberalizado. Lo que supone dejar de lado nuestro sistema tradicional de gestión pública para pasar a un método extraño a nuestra tradición jurídica, basado en la regulación de la empresa privada. [...] se trata de articular la prestación de los servicios esenciales mediante el recurso a la competencia, alcanzando la consideración de servicio público tan solo a determinadas prestaciones, aquellas que el juego concurrencial del mercado no satisface de forma idónea, y perdiendo los poderes públicos el papel de prestador del servicio para asumir la posición de regulador» ${ }^{77}$.

Dentro del Derecho de la Unión Europea se diferencia entre los «servicios de interés general» (SIG) y los «servicios de interés económico general» (SIEG) —ambos conceptos más precisos que el genérico de «servicio público»— entre los valores comunes por su contribución a la cohesión económica y social y de promoción de la competitividad, por facilitar a las empresas servicios eficientes que les mejoran sus condiciones productivas (art. 16) ${ }^{78}$. Se ha de señalar que se está abriendo camino un nuevo concepto, el de los «servicios sociales de interés general» (SSIG), que se basa en la conclusión 31 de la Estrategia acordada por el Consejo Europeo de Lisboa de marzo de 2000.

No parece que el orden europeo de los servicios públicos esté construido de un modo definitivo y válido para todos los diferentes supuestos, que se incrementan con la ampliación y las economías de los nuevos Estados miembros. Se necesita aclarar el significado de los servicios de interés general en su concepto, participación, gestión y garantía por parte de los poderes públicos, alcance de los objetivos de interés general, de sus ámbitos y evaluación, establecimiento de las bases normativas comunes, etcétera.

En la declaración sobre los servicios de interés económico general, recogida en el anexo II de las conclusiones del Consejo de Niza, el cumplimiento de los fines de los servicios debe efectuarse con respeto a las demandas de los consumidores que desean precios aceptables, así como un acceso en igualdad a los servicios de calidad en su inserción económica, territorial y social; considerándolos como ciudadanos y consumidores que participan en una gestión eficaz y transparente.

\footnotetext{
77 Domínguez-Berrueta, M., «Prólogo» a Sendín García, M. A., Regulación y servicios públicos, Granada, Comares, 2003, p. XIX.

${ }^{7}$ JENNY, F., «Des services publics dans le marché et hors marché: service public, service d'intérêt général ou service d'intérêt économique général», en Europe, service public et concurrence, Actes du colloque de l'AJE-AFEC du 13 mai 2004 sur le Livre vert SIG, Petites Affiches 2004, spécial, 239, p. 6. Dony, M., Levrat, N., Rodrigues, S. y Vandamme, J., Les services d'intérêt général en Europe, rapport d'étude pour le Comité des régions, E3/2004, Buruselas, OPOCE, 2005.
} 
Ante las nuevas formas de regulación de los servicios, la externalización de su gestión precisa de una nueva definición del concepto de servicio, de su regulación y control presupuestario, así como de técnicas de evaluación de su calidad y eficacia.

\subsection{Los servicios de interés general}

El concepto de «servicios de interés general» (SIG) no figura en el Tratado y deriva del de «servicios de interés económico general» (SIEG) (arts. 16 y 86.2), con un sentido más amplio que «abarca los servicios, sometidos o no a la disciplina de mercado, que las autoridades públicas consideran de interés general y están sometidos a obligaciones específicas de servicio público» ${ }^{79}$. Su calificación como «servicios de interés general» está condicionada por la consideración económica de si es «susceptible de ser ejercida, al menos en principio, por una empresa privada con fin lucrativo» ${ }^{80}$, por si tiene «un interés económico general que presente caracteres específicos en relación con los que revisten otras actividades de la vida económica» (STJCE 10 de diciembre de 1991, As. C-179/90, Merci Convenzionali Porto de Genova). Se han visto afectados por los procesos de liberalización en telecomunicaciones (Directiva 96/19, de 13 de marzo de 1996), transportes ferroviarios (Directiva 91/440/CEE, de 29 de julio de 1991), energía eléctrica y servicios postales (Directiva 97/67/CE, de 15 de diciembre de 1997), que se aceleraron a partir del Consejo Europeo de Lisboa de marzo de 2000.

La Unión reconoce la competencia de los Estados miembros para establecer el régimen de prestación de los servicios públicos «en ausencia de armonización comunitaria»: «los Estados miembros disponen de amplias facultades para decidir la manera de organizar los servicios de interés general. [...] son libres de decidir si las mismas prestan un servicio de interés general o si confían dicha tarea a otra entidad (pública o privada)» ${ }^{81}$. En todo caso, la

\footnotetext{
${ }^{79}$ Comunicación de la Comisión al Parlamento Europeo, al Consejo, al Comité Económico y Social Europeo y al Comité de las Regiones-Libro Blanco sobre los servicios de interés general, [COM/2004/ 0374 final], especifica en torno al concepto de servicios de interés económico general que «la expresión servicios de interés general sólo se utiliza en el Libro Blanco cuando el texto alude también a los servicios no económicos o cuando no es necesario precisar la naturaleza económica o no económica de los servicios a los que se hace referencia». MARTínez LóPEZ-MuÑIZ, J. L., «Servicio público, servicio universal y 'obligación de servicio público' en la perspectiva del Derecho Comunitario: Los servicios esenciales y sus regímenes alternativos», en $R A n A P, 39,2000$, pp. 25-52; «En torno a la nueva regulación de los servicios esenciales económicos en red. (A propósito de la nueva Ley General de Telecomunicaciones y su sistema conceptual), en El Derecho administrativo en el umbral..., cit., III, pp. 27952824. Maillo González-Orús, J., Servicios de interés general y artículo 86 del Tratado CE: una visión evolutiva, Madrid, Instituto de Estudios Europeos de la Universidad San Pablo-CEU, 2005. SENdín García, M. A., Hacia un servicio público europeo. El nuevo derecho de los servicios públicos, Granada, Comares, 2003, pp. 179 y ss. RodRíGUES, S., «Les qualifications concurrentes des activités d'intérêt général en droit communautaire», en AJDA, 2, 2006, pp. 84-90.

${ }^{80}$ Decisión de la Comisión 95/364/CE, de 28 de junio de 1995, Régie belge des voies aériennes.

${ }^{81}$ «Libro Blanco sobre los servicios de interés general»(COM 2004, 374 final).
} 
prestación deberá realizarse conforme a las reglas de la libre competencia (art. $81)^{82}$, a la posición dominante (art. 82) o al régimen de ayudas públicas (art. 87), aunque podrá ser excluida de las mismas si se trata de «servicios públicos de interés general».

La Declaración del Consejo Europeo de Niza de diciembre de 2000 hizo constar «la importancia de los principios de neutralidad, de libertad y de proporcionalidad, que garantizan que los Estados miembros son libres de definir el cometido, así como las modalidades de gestión y de financiación de los servicios de interés económico general, mientras que la Comisión asume la responsabilidad de velar por el respeto de las normas del mercado interior y de la competencia». Mostró, además, su preocupación por las «condiciones de seguridad jurídica y de viabilidad económica que garanticen, entre otros, los principios de igualdad de trato, de calidad y de continuidad en los servicios», así como la articulación de su financiación «con la aplicación de las normas relativas a las ayudas estatales».

La puesta en marcha de estos principios aplicados a los servicios de interés general, que eran una seña de identidad del Estado social y democrático de Derecho en Estados como Alemania y Francia, ha dado lugar a muchas dificultades $^{83}$. El debate y estudio se inició con el «Libro Verde sobre los servicios de interés general» de 21 de mayo de $2003^{84}$. Posteriormente se elaboró el llamado «Libro Blanco sobre los servicios de interés general» [COM (2004) 374 final] que partió del «consenso sobre la importancia vital que los servicios de interés general revisten para las sociedades europeas [...] deben prestarse teniendo siempre presente, en primer lugar, a los usuarios». Recoge los resultados de la participación y del acuerdo logrado para «garantizar una combinación armoniosa de mecanismos de mercado y misiones de servicio público», como «objetivos compatibles». Reconoció que la Unión y los Estados comparten la responsabilidad de los servicios de interés general, según el principio subyacente en el artículo 16 del Tratado, así como el derecho de los Estados a imponer obligaciones de servicio público específicas a los agentes económicos también formulado implícitamente por el artículo 86.2. A juicio de la Comisión, «la creación de un mercado interior ha contribuido sensiblemente a una mayor eficiencia, haciendo así más asequible una serie de servicios, como se aprecia particularmente en los sectores de telecomunicaciones y transportes».

\footnotetext{
82 COMISIÓn EuropeA, Comunicación relativa a los acuerdos de menor importancia que no restringen la competencia de forma sensible en el sentido del apartado 1 del artículo 81 del Tratado CE (de minimis), DO C 368, 22 de diciembre de 2001. Directrices relativas al concepto de efecto sobre el comercio contenido en los artículos 81 y 82 del Tratado, DO C 101, 27 de abril de 2004. SENDín GARCíA, M. A., Hacia ..., cit., pp. 263-270.

${ }^{83}$ Rodrigues, S., «Les qualifications concurrentes des activités d'intérêt général en droit communautaire», AJDA, 2, 2006, pp. 84-90.

${ }^{84}$ Libro Verde de la Comisión, de 21 de mayo de 2003, sobre los servicios de interés general [COM (2003) 270 final, Diario Oficial C 76 de 25.3.2004]. Fue objeto de la resolución del Parlamento Europeo de 13 de enero de 2004.
} 
En la «Propuesta de Directiva del Parlamento Europeo y del Consejo, de 13 de enero de 2004 [COM (2004) 2 final], relativa a los servicios en el mercado interior ${ }^{85}$, se recoge la posición del Consejo y, sobre todo, del Parlamento, en sesión de 16 de febrero de 2006, conforme a las enmiendas aprobadas, sobre el régimen y alcance de los servicios de interés general:

a) Se excluye del tratamiento de los servicios los prestados por las autoridades públicas en cumplimiento de sus obligaciones sociales, culturales, educativas o legales, así como algunos servicios de interés económico general. En el considerando 8 bis introducido por enmienda se declara que la Directiva «no se debe aplicar a los servicios de interés general prestados o definidos por los Estados miembros en cumplimiento de sus obligaciones de protección del interés general [...] solamente son de aplicación si las actividades [...] están abiertas a la competencia y no obligan a los Estados miembros a liberalizar servicios de interés general ni a privatizar organismos de Derecho público ni a eliminar monopolios como las loterías o determinados servicios de distribución». Conforme al artículo 1.3 «no se aplicará a la liberalización de los servicios de interés económico general reservados a entidades públicas o privadas ni a la privatización de entidades públicas prestadoras de servicios», ni a «la libertad de los Estados miembros para definir, conforme al Derecho comunitario, los servicios que consideren de interés económico general, la forma en que estos servicios deben organizarse y financiarse y las obligaciones específicas a que deben estar sometidos» (art. 1.3), ni «a los servicios que persiguen un objetivo de bienestar social» (art. 1.6) ${ }^{86}$.

b) El Parlamento consideró servicio «cualquier actividad económica prestada normalmente a cambio de una remuneración», aunque, a efectos de la exclusión de la Directiva, definió los «servicios de interés económico general», siguiendo los criterios jurisprudenciales, como «los servicios definidos como tales por los Estados miembros y a los que se imponen obligaciones específicas de servicio público atribuidas al prestador de servicios por el Estado miembro en cuestión con el fin de garantizar la consecución de ciertos objetivos de interés general» (art. 4.1 ter).

c) La «razón imperiosa de interés general» abarca el «orden público, seguridad pública y salud pública» (Cdo. 29), siguiendo la casuística jurisprudencial, entre otros, «la protección del orden público, la seguridad pública, la salud pública, la preservación del equilibrio financiero del régimen de seguridad social, incluida una atención sanitaria equilibrada para todos, la protección de los consumidores, de los destinatarios de servicios y de los trabajadores, la equidad de las transacciones comerciales, la lucha contra el

\footnotetext{
${ }^{85}$ De Schutter, O. y FrancQ, S., «La proposition de directive relative aux services dans le marché intérieur: reconnaissance mutuelle, harmonisation et conflits de lois dans l'Europe élargie», en Cahiers de Droit européen, 5-6, 2005, pp. 603-660.

${ }^{86}$ Royer, E., «Les services sociaux sont exclus du champ de la directive Bolkestein», en AJDA, 9, 2006, p. 460.
} 
fraude, la protección del medio ambiente, incluido el entorno urbano, la sanidad animal, la propiedad intelectual, la conservación del patrimonio artístico nacional y los objetivos de la política social y cultural» (art. 4.7 bis). En los considerandos previos se hace referencia expresa a los servicios de bienestar social «manifestación de los principios de solidaridad y de cohesión social [...] Estos servicios están a menudo completamente desprovistos de afán de lucro, por lo que los beneficios que de ellos se obtienen pueden no tener relación con ninguna consideración de orden económico» ${ }^{87}$.

d) «El pago de una tasa por los destinatarios para contribuir a la financiación del funcionamiento del sistema no constituye, en sí, una remuneración, ya que el servicio sigue financiándose básicamente con fondos públicos» (Cdo. 15).

En la STJCE de 22 de mayo de 2003 (As. 18/01, Korhonen y otros) las necesidades de interés general, que no tienen carácter industrial o mercantil, son las que, «por una parte, no se satisfacen mediante la oferta de bienes o servicios en el mercado y que, por otra, por razones de interés general, el Estado decide satisfacerlas por sí mismo o respecto de las cuales quiere conservar una influencia determinante» (STJCE de 10 de noviembre de 1998, As. C-360/96, BFI Holding). Para apreciar la falta de tal carácter se han de tomar en consideración todas las circunstancias de su creación y las condiciones en que ejerce su actividad, «incluidas en particular la falta de competencia en el mercado, la falta de ánimo de lucro como objetivo principal, la no asunción de los riesgos derivados de dicha actividad, así como la eventual financiación pública de la actividad de que se trate». De modo que, «si el organismo opera en condiciones normales de mercado, tiene ánimo de lucro y soporta las pérdidas derivadas del ejercicio de su actividad, es poco probable que las necesidades que pretende satisfacer no tengan carácter industrial o mercantil».

La Comisión en la Comunicación sobre los servicios de interés general en Europa (COM 2000-580) los valoró de modo que «los medios utilizados para cumplir la misión de interés general no crearan distorsiones innecesarias del comercio. [...] hay que asegurar que ninguna restricción a las normas del Tratado CE y, en especial, las restricciones de la competencia y las limitaciones de las libertades del mercado inferior excedan lo necesario para garantizar el cumplimiento efectivo de la misión».

\subsection{Los servicios de interés económico general}

El concepto de «servicios de interés económico general» (SIEG) no está definido ni por los artículos 16 y 86.2 del Tratado ni por el Derecho deriva-

87 Ortiz Díaz, J., «El horizonte..., cit., pp. 98-102. 
do, disponiendo este último que «las empresas encargadas de la gestión de servicios de interés económico general quedarán sometidas a las normas de este Tratado, en especial a las de la competencia», recogido en los artículos 31 y $295^{88}$. Su significado fue establecido en el «Libro Blanco» sobre los servicios de interés general: «aquellos servicios de naturaleza económica a los que los Estados miembros o la Comunidad imponen obligaciones específicas de servicio público en virtud del criterio del interés general». Puso como ejemplo «ciertos servicios prestados por las grandes industrias en redes, como el transporte, los servicios postales, la energía y las comunicaciones. Sin embargo, esta expresión abarca igualmente otras actividades económicas sometidas también a obligaciones de servicio público» ${ }^{89}$.

En la «Propuesta de Directiva del Parlamento Europeo y del Consejo, de 13 de enero de 2004 [COM (2004) 2 final], relativa a los servicios en el mercado interior», el Parlamento consideró servicio «cualquier actividad económica prestada normalmente a cambio de una remuneración», aunque, a efectos de su exclusión de la Directiva, definió los «servicios de interés económico general», siguiendo los criterios jurisprudenciales, como «los servicios definidos como tales por los Estados miembros y a los que se imponen obligaciones específicas de servicio público atribuidas al prestador de servicios por el Estado miembro en cuestión con el fin de garantizar la consecución de ciertos objetivos de interés general» (art. 4.1. ter). En estos servicio aparece «la función de garante del Estado en todo su vigor a través de las llamadas obligaciones de servicio público, entre las cuales el servicio universal es la más típica y característica y donde mejor se aprecia esa nueva función del Estado garante. [...] el nuevo concepto del servicio económico de interés general que se alumbra en el marco del derecho comunitario es la expresión del moderno derecho administrativo y el concepto desde el que considerar la posición del Estado en la nueva economía» ${ }^{90}$.

Por «obligaciones de servicio público» se entienden las «específicas impuestas por los poderes públicos al proveedor del servicio con el fin de garantizar la consecución de ciertos objetivos de interés público, por ejemplo en materia de transporte aéreo, ferroviario y por carretera, o en el sector de la energía. Esta obligación puede aplicarse a escala regional, nacional o comunitaria» ${ }^{11}$. Según la STJCE de 26 de mayo de 1982, As. 149/79, los po-

\footnotetext{
${ }^{88}$ JimÉnez Blanco, A., «Servicio público, interés general, monopolio: Recientes aportes del Tribunal de Justicia de la Comunidad Europea», en REDA, 84, 1994.

${ }^{89}$ El informe del Senado francés 257 (2004-2005) dedujo de la terminología comunitaria que «la Unión europea distingue dos tipos de servicios públicos: los servicios públicos no mercantiles (SIG) [...] y los servicios públicos mercantiles (SIEG)».

90 Rodríguez-Arana, J., «Servicio..., cit., pp. 383 y 385.

${ }^{91}$ Comunicación de la Comisión al Parlamento Europeo, al Consejo, al Comité Económico y Social Europeo y al Comité de las Regiones-Libro Blanco sobre los servicios de interés general [COM (2004) 0374 final], Anexo conforme a las definiciones contenidas en el Libro Verde. También se recogieron en el Libro Blanco. RodrígueZ-Arana, J., «Servicio..., cit., p. 389, señala el desconcierto que este con-
} 
deres públicos son «la encarnación de la soberanía del Estado y como tales confieren a quienes los ostentan la facultad de ejercitar prerrogativas que sobrepasan el ámbito del Derecho común, privilegios y poderes coercitivos que obligan a los ciudadanos». Como reconoció la jurisprudencia, «los Estados tienen un amplio poder de apreciación en cuanto a la concreción de lo que consideran de interés económico general [...] que sólo puede ser cuestionado por la Comisión en caso de error manifiesto» (STJPI de 15 de junio de 2005, As. T-17/02, Freed Olsen). Por consiguiente, entran dentro de este concepto ciertos servicios prestados por las grandes industrias de redes como el transporte, los servicios postales, la energía y las comunicaciones. Sin embargo, esta expresión abarca igualmente otras actividades económicas sometidas también a obligaciones de servicio público» ${ }^{92}$.

El régimen no se aplica con criterio subjetivo por la naturaleza pública o privada de la empresa, sino por el criterio material industrial o comercial del interés general del servicio prestado, porque el concepto de «empresa» comprende «cualquier entidad que ejerza una actividad económica con independencia del estatuto jurídico de dicha entidad y de su modo de financiación» (STJCE de 23 de abril de 1991, Höfner y Elser, C 41/90) ${ }^{93}$, entendiendo como actividad la que «consiste en ofrecer bienes o servicios en un mercado determinado» o la que tiene carácter económico cuando es susceptible de ejercerse con un agente privado con fin lucrativo (STJCE de 16 de junio de 1987, Comisión c. Italia, C-118/85). La STJCE de 16 de noviembre de 1995, Féderation française des societés d'assurance e.a.c. Ministre de l'agriculture et de la pêch, C-244/94, calificó de empresa a «un organismo con fin no lucrativo que gestiona un régimen de seguro de vejez destinado a completar un régimen de base obligatorio, establecido por ley, a título facultativo y funcionando con respeto a las reglas establecidas por el poder reglamentario, fundamentalmente en lo que afecta a las condiciones de adhesión, cotizaciones y prestaciones según el principio de capitalización ${ }^{94}$.

Así lo conforma el «Libro Blanco»: «El término empresa pública también suele utilizarse, por lo general, para definir el régimen de propiedad del proveedor del servicio. El Tratado prevé a este respecto una estricta neutralidad. Con arreglo al Derecho comunitario, es irrelevante que los proveedores de

\footnotetext{
cepto ha producido y la identificación que se ha querido realizar entre el servicio universal y las obligaciones de servicio público: «Sin embargo, la realidad es que ahora el Estado interviene en la vida económica desde enfoques abiertos, no unilaterales. El servicio público, pues, queda para los supuestos, que pueden darse en circunstancias especiales, de reserva, exclusividad y titularidad de la actividad de que se trate».

${ }^{92}$ García de COCA, J.A., «Régimen jurídico de las empresas encargadas de la gestión de servicios de interés económico general», en Noticias de la Unión Europea, 232, 2004, pp. 7-29.

${ }_{93}$ SSTJCE de 30 de abril de 1974, As. 155/1973, Sacchi, y 18 de junio de 1975, AS. 94/1975, IGAV/ ENCC.

${ }^{94}$ SSTJCE de 21 de septiembre de 1999, Albany, C-67/96, y 12 de septiembre de 2000, Pavlov e.a., C-180/98.
} 
servicios de interés general sean públicos o privados, todos están sujetos a los mismos derechos y obligaciones».

El Tratado de Ámsterdam consideró que los servicios de interés económico general figuraban «entre los valores comunes de la Unión, así como de su papel en la promoción de la cohesión social y territorial», por lo que la Comunidad y los Estados «velarán por que dichos servicios actúen con arreglo a principios y condiciones que les permitan cumplir su contenido» (art. 16) ${ }^{95}$. La aplicación de las normas sobre competencia se introdujo por el artículo 4 al exigir que «la acción de los Estados miembros y de la Comunidad comporta [...] el establecimiento de una política económica fundada [...] en el mercado inferior y la definición de objetivos comunes, conduce formalmente al respecto del principio de una economía abierta en la que la concurrencia es libre». El artículo 86.1 dispuso que «los Estados miembros en lo que afecta a las empresas públicas y aquellas a las que concedan derechos especiales o exclusivos no establezcan ni mantengan medidas contrarias a las normas del presente tratado, especialmente a las previstas por los artículos 12 [prohibición de discriminaciones por nacionalidad] y 81 a 89 incluidos» ${ }^{96}$. Se producirá «en la medida en que la aplicación de dichas normas no impida, de hecho o de derecho, el cumplimiento de la misión específica a ellas confiada» (art. 86.2 $)^{97}$. La referencia de las normas de competencia a la compatibilidad con ellas se basa en la neutralidad respecto a la propiedad pública o privada de las empresas (art. 295), la libertad de los Estados para definir los servicios de interés general y la proporcionalidad de las restricciones de la competencia para la realización eficaz de sus misiones.

La excepción al principio de concurrencia del artículo 86.2 ha sido aplicada de modo restrictivo por la jurisprudencia, que considera como actividades de mercado muchas de las que venían siendo calificadas de «servicio público», como el transporte aéreo, el servicio postal, el suministro eléctrico, las telecomunicaciones, etcétera en cuanto eran económicas, haciendo la salvedad a las actividades no económicas sin impacto sobre los servicios de interés general. El Tribunal de Justicia ha incluido entre las excepciones, por tratarse de auténticos servicios públicos relacionados con las actividades de la autoridad pública por ejercicio de potestades, a los relativos a la seguridad interior y exterior, justicia, asuntos exteriores y otros en ejercicio del poder público, como la educación nacional, la protección de los consumidores, la salud pública (Decisión de la Comisión 82/331/CEE de 17 de diciembre de 1981, Navewa v. Anseau) y los regímenes básicos obligatorios de la seguri-

\footnotetext{
95 Sendín García, M. A., Hacia..., cit., pp. 337-343.

${ }^{96}$ Como declaró la STJCE de 18 de junio de 1998, Comisión c. Italia, las normas comunitarias «imponen a los Estados miembros no tomar o mantener en vigor medidas susceptibles de eliminar el efecto útil de las reglas de competencia aplicables a las empresas».

97 Sendín García, M. A., Hacia..., cit., pp. 335-337.
} 
dad social ${ }^{98}$. La STJCE de 18 de junio de 1998, C-266/96, Corsica Feries France c. Grupo Antichi Ormeggiatori del porto di Genova, entendió que el pilotaje de barcos en los puertos para las operaciones de amarre tiene las características propias de un servicio de interés económico general conforme al artículo 86 del Tratado.

La STJCE de 19 de enero de 1994, As. C-364/92, Sat Fluggesellschaft c.Eurocontrol, calificó de materia sin carácter económico y excluida del régimen de la competencia por tratarse de una «actividad de autoridad pública» las «prerrogativas relativas al control de policía del espacio aéreo, que son típicamente prerrogativas públicas. No presentan carácter económico que justifique la aplicación de las reglas de la concurrencia del Tratado ${ }^{99}$. Del mismo modo consideró de interés general las medidas para la protección del medio ambiente «que son prerrogativas típicas el poder público» (SSTJCE 27 de abril de 1994, As. C-393/92, Commune d'Almelo et Energiebedrijfi NV; 18 de marzo de 1997, C-343/95, Cali \& Figli c. Servici ecologici Porto di Geneva,), la ordenación del territorio (STJCE 23 de octubre de 1997, As. C159/94, Comisión v. Francia) o la constitución de equipos deportivos nacionales (STJCE de 12 de diciembre de 1974, 36/74, Walrave). También utilizó el concepto de «objetivo social» en la STJCE de 17 de febrero de 1993, As. C-159 y 160/91, Poucet \& Pistre, respecto a «organismos de servicio público de la seguridad social que cumplen una función de carácter exclusivamente social. Esta actividad, en efecto, está fundada en el principio de la solidaridad nacional y desprovista de todo fin lucrativo [...] no es una actividad económica y, desde luego, los organismos que se encargan de ello no constituyen empresas en el sentido de los artículos 85 y 86 del Tratado». En los mismos términos la STJCE de 22 de enero de 2002, C-218-00, INAIL.

Para garantizar los derechos de los consumidores y usuarios (acceso y asequibilidad de los servicios, integridad física, seguridad y fiabilidad, continuidad, nivel de calidad, variedad de oferta, transparencia y acceso a la información) son necesarias «autoridades reguladoras independientes, con funciones y competencias claramente definidas, entre ellas, poderes sancionadores (medios de controlar la incorporación y vigilar el cumplimiento de las disposiciones de servicio universal). [...] deberían establecerse disposiciones que prevean la representación y participación activa de los consumidores y

\footnotetext{
98 «Libro Blanco sobre los servicios de interés general», de 2004: «Los servicios sociales de interés general tienen un papel concreto que desempeñar en cuanto parte integrante del modelo europeo de sociedad. Basados como están en el principio de solidaridad, los servicios sociales y sanitarios de interés general están centrados en la persona, garantizan a los ciudadanos el disfrute efectivo de sus derechos fundamentales y un elevado nivel de protección social, y refuerzan la cohesión social y territorial. [...] la normativa comunitaria puede tener alguna incidencia en los instrumentos de prestación y financiación de dichos servicios. [...] conveniente desarrollar un planteamiento sistemático con vistas a la determinación y el reconocimiento de las características específicas de los servicios sociales y sanitarios de interés general, y precisar el marco en el que esos servicios funcionan y pueden modernizarse».

99 Las SSTJCE de 26-5-1982, As. 149/1979, Comisión v. Bélgica, y 3-6-1986, AS. 307/1984, Comisión v. Francia, diferenciaron entre las actividades de autoridad y las de contenido económico.
} 
usuarios en la definición y evaluación de los servicios, la instauración de vías de recurso y mecanismos apropiados de compensación ${ }^{100}$ y la existencia de una cláusula evolutiva que permita adaptar las exigencias en función de las necesidades e inquietudes cambiantes de los consumidores y usuarios y de la variedad del entorno económico y tecnológico».

Precisamente en esta línea garantista de los servicios de interés económico general por su papel en la cohesión social y territorial, el artículo II-36 del proyecto de Constitución para Europa dispone que la Unión «reconoce y respeta el acceso a los servicios de interés económico general, [...] con el fin de promover la cohesión social y territorial de la Unión ${ }^{101}$. El artículo III-6 encomienda a la Unión y a los Estados miembros velar por que «dichos servicios actúen con arreglo a principios y condiciones, económicos y financieros en particular, que les permitan cumplir su cometido. Dichos principios y condiciones se definirán mediante leyes europeas». Todo esto como salvedad a lo dispuesto por los artículos III-55, III-56 y III-136, referidos a las normas sobre la competencia por las empresas de gestión de servicios de interés económico general, a las ayudas de los Estados, a los transportes o al reembolso de obligaciones inherentes a la noción de servicio público.

En sentido subjetivo la jurisprudencia ha exigido que para calificar como organismo de Derecho público a una entidad debe cumplir los tres requisitos acumulativos que exige el artículo $1.2^{\circ}$. b) de la Directiva 93/37: ser un organismo creado para satisfacer específicamente necesidades de interés general que no tengan carácter industrial o mercantil, estar dotado de personalidad jurídica y depender en su actividad estrechamente del Estado, de entes territoriales o de otros organismos de Derecho público. Además, el mero estatuto de Derecho privado no es un criterio que pueda excluir su calificación como entidad adjudicadora en el sentido de esta Directiva, sino la naturaleza industrial o mercantil de la actividad que desarrolle (STJCE 15 de mayo de 2003, As. 214/00, Comisión v. España) ${ }^{102}$. La STJCE de 16 de octubre de 2003 (As. 214/00, Comisión v. España) invocó el criterio de la Comisión de que el concepto que siempre ha distinguido al organismo de Derecho público es que se crea «para satisfacer específicamente necesidades de interés general que no tengan carácter industrial o mercantil, mientras que las

\footnotetext{
${ }^{100}$ Las SSTJCE de 24 de julio de 2002, C-280/00, Altmark Trans, y 24 de noviembre de 2003, C-34/ 01 a 39/01, Enrisorse SpA, establecieron las condiciones para que la compensación por servicios no tenga carácter de ayuda de Estado.

101 Lyon-Caen, A. y Champeil-Desplats, V., Services publics et droits fondamentaux dans la construction européenne, Paris, Dalloz, 2001.

${ }^{102}$ La STJCE de 10 de mayo de 2001, C-223/99 y 260/99, Agorá Srl et Excelsior Snc, declaró que un organismo que satisface necesidades de interés general y sin fin lucrativo, «cuya gestión se base en criterios de rendimiento, de eficacia y de rentabilidad y que opere en un medio de concurrencia» no es un organismo adjudicador. Las SSTJCE de 11 de enero de 2005, As. C-26/03, Stadt Halle, y 13 de octubre de 2005, As. C-458/03, Parking Brixen $\mathrm{GmbH}$, expusieron que la transformación de una empresa específica de prestación de servicios en sociedad anónima, aun cuando su capital siga siendo público, no puede beneficiarse de una concesión de servicio público sin concurrencia previa.
} 
empresas públicas actúan para satisfacer necesidades de carácter industrial o mercantil» $^{103}$.

Se ha diferenciado entre contrato y concesión. El artículo 1.d) de la directiva 93/37 sobre mercados públicos definió la concesión como «un contrato con los mismos caracteres que los del apartado a), es decir, contrato público, con la excepción de que la contrapartida de las prestaciones consiste únicamente en el derecho de explotar la obra o mediante el pago de un precio» ${ }^{104}$. La STJCE de 26 de abril de 1994, C-272/91, Comisión c. Italia, rechazó calificar de concesión a un contrato en el que no se transfería responsabilidad al concesionario. En la 10 de noviembre de 1998, C-360/96, Gemeente Arnhem c. BFI Holding, negó el carácter de concesión a un contrato que no preveía remuneración por el derecho de explotar el servicio ni riesgos en la misma. En la STJCE de 7 de diciembre de 2000, C-324/98, Teleaustria y Telefonadress, se establecieron las reglas y principios derivados del Código de los contratos públicos aplicables a las concesiones: de igualdad que se deriva del de concurrencia; de transparencia, para garantizar condiciones de concurrencia no falseada y asegurada por los medios apropiados; proporcionalidad, de modo que cada medida elegida sea necesaria y apropiada respecto al objetivo fijado; reconocimiento mutuo de las especificaciones o calificaciones exigidas en otro Estado miembro, y protección de los derechos de los particulares.

La Directiva 80/723, de 25 de junio de 1980, sobre transparencia de las relaciones financieras entre los Estados miembros y las empresas públicas, que ha sido referente de la normativa comunitaria sobre ellas, las definió como «toda empresa en la que los poderes públicos pueden ejercer directa o indirectamente una influencia dominante sobre su propiedad, participación financiera o las reglas que la rigen». Por tanto, es la «influencia dominante» de una autoridad pública el principal criterio para considerarla como tal, cuando se ejerce por medio del nombramiento de sus directivos o del control de sus decisiones, con independencia de cuál sea la participación en la propiedad. Respecto a su régimen jurídico se distingue entre las regidas por su propio derecho de carácter público o especial cualquiera que fuera su nombre (establecimiento público, corporación pública, empresa nacional, pública o es-

\footnotetext{
${ }^{103}$ La STJCE de 15 de enero de 1998, C-44/96, Mannesnmann, consideró que satisfacía necesidades de interés general la fabricación de los impresos oficiales para los pasaportes, los permisos de conducir y los carnés de identidad. La de 10 de noviembre de 1998, C-360/96, Gerneente Arnhem, en cuanto a la recogida y tratamiento de los residuos sólidos urbanos. La de 17 de diciembre de 1998, C-353/96, Comisión c. Irlanda, lo hizo respecto al mantenimiento de los bosques nacionales y de la industria forestal. La de 3 de octubre de 2000, C-380/98, Univesity of Cambridge, sobre la gestión universitaria. Por la de 7 de diciembre de 2000, C-3224/98, Telaustria et Telefinadress, para la gestión de las redes públicas de telecomunicaciones. La de 25 de febrero de 2001, C-230/99, Comisión c. Francia, para la construcción de viviendas sociales por los organismos públicos de ordenación y construcción de alojamientos y rehabilitación.

${ }^{104}$ Existe una Comunicación interpretativa de la Comisión sobre las concesiones en Derecho comunitario (DOCE C 121, de 29 de abril de 2000).
} 
tatal, etcétera), de las regidas por el derecho privado o común (denominadas habitualmente sociedades nacionales o estatales) sujetas al Derecho mercantil y al laboral para sus empleados.

La resolución 94/C 48/01, del Consejo de 7 de febrero de 1994, sobre el servicio universal de las telecomunicaciones, declaró que «el objetivo principal de la política comunitaria en materia de telecomunicaciones es la liberalización de todos los servicios públicos de telefonía vocal y el mantenimiento, al mismo tiempo, del servicio universal». Se compaginó la liberalización de un servicio de contenido comercial asumiendo que, cuando no fuera atractivo, la autoridad nacional garantizara el «servicio universal» necesario para todos los ciudadanos. Este es el caso que se produce cuando «sólo pueda suministrarse con pérdidas o en condiciones de coste que se alejen de las normas comerciales habituales, este servicio podrá financiarse, con la aprobación de las autoridades reglamentarias nacionales, mediante transferencias internas, cuotas de acceso u otros mecanismos que tengan debidamente en cuenta los principios de transparencia, no discriminación y proporcionalidad». De este modo se hacen compatibles el ejercicio de la libertad económica y la competencia en el mercado con la garantía de la calidad de vida por la utilización de servicios imprescindibles, sin imponer al poder público el establecimiento del servicio, permitiéndole compensar a los agentes económicos de los déficits derivados de la prestación, respetando las reglas de la competencia, con transparencia, no discriminación y proporcionalidad. Como expone RAPP «no se trata del concepto de servicio público en el sentido tradicional del término. Es una especie de síntesis entre el objetivo de un mercado más comercial y la preocupación de una cierta continuidad del servicio, una especie de intento de conciliación de los principios del servicio público con los de la economía de mercado» ${ }^{105}$.

El artículo 2 de la Ley 32/2003, de 3 de noviembre, de Telecomunicaciones, las califica de «servicios de interés general que se prestan en régimen de libre competencia». Ahora bien, las distingue de las que se prestan en régimen de «servicio público», que son las «telecomunicaciones para la defensa nacional y la protección civil» (art. 4) y las del Título III («obligaciones de servicio público y derechos y obligaciones de carácter público en la explotación de redes y en la prestación de servicios de comunicaciones electróni-

\footnotetext{
105 Citado por Rodríguez-Arana, J., «Servicio..., cit., p. 393: «El concepto de servicio universal es la expresión en el mundo del derecho administrativo de los postulados del pensamiento abierto, dinámico y complementario. Además, demuestra a las claras que el relativismo y la instrumentalidad son notas que acompañan al propio derecho administrativo en su largo peregrinar. ¿Por qué? Porque se complementan elementos del régimen de servicio público — continuidad, regularidad_ y del mundo del mercado — no monopolio - en su ejercicio de integración que, de verdad, refleja la actualidad de las técnicas del derecho administrativo aplicadas a la realidad del momento, sin necesidad de acudir a una añoranza del pasado queriendo ver lo que ya no existe, porque no puede existir. [...] Por tanto, la tarea de la Administración pública es muy importante para preservar el servicio universal. Ni puede abusar de su posición para someter al empresario a situaciones irracionales, ni debe tolerar que el mercado castigue a los más débiles. Por eso, hoy más que nunca, el derecho administrativo se presenta como el derecho del poder para la libertad».
} 
cas) (arts. 20-38). Las imposiciones del servicio público obligan a la consecución de los objetivos del artículo 3. En este caso el concepto fundamental es del «servicio universal», como el «conjunto de servicios cuya prestación se garantiza para todos los usuarios finales con independencia de su localización geográfica, con una calidad determinada y a un precio asequible» (art. 22). Para garantizarlo, la Comisión del Mercado de las Telecomunicaciones establecerá un mecanismo de compensación y reparto de costes en el Fondo nacional del servicio universal que garantiza la financiación del servicio universal (art. 24).

Precisamente el mercado de las telecomunicaciones y el de la energía son ejemplo de las dificultades que se derivan de una liberalización cuando la infraestructura se corresponde con una red unitaria, por el control y predominio de los operadores establecidos y las dificultades de los nuevos, que tienen que utilizar la misma red. De tal modo que cuando las infraestructuras en red «son realmente unitarias y constituyen un cauce de paso necesario para acceder a un mercado, conduce por la propia naturaleza de las cosas a un régimen de monopolio, que es difícil de compatibilizar con una situación de competencia. [...] El resultado es, con excepciones, el de un monopolio u oligopolio más o menos larvado, es decir, de competencia imperfecta en los sectores de la red, donde unas pocas empresas concentran un alto porcentaje del mercado» ${ }^{106}$.

En el proyecto de Constitución para Europa de 29 de octubre de 2004 se destaca la importancia de los servicios de interés económico general ya formulada en el Tratado de Ámsterdam. Aparecen en la Carta de los derechos fundamentales siguiendo el camino iniciado por el artículo III-122 de la Carta del Consejo de Niza de diciembre de 2000. Conforme al artículo II-36 se «reconoce y respeta el acceso a los servicios de interés económico general, tal y como disponen las legislaciones y prácticas nacionales, de conformidad con la Constitución, con el fin de promover la cohesión social y territorial de la Unión». Sin embargo, no constan entre los «valores» (art. I-2) ni entre los «objetivos de la Unión» (art. I-3), aun cuando se reconoce su importancia dentro de las cláusulas generales de la Parte III, como «servicios a los que en la Unión todos conceden valor, así como de su papel en la promoción de la cohesión social y territorial de ésta», para lo que por medio de leyes europeas se fijarán los principios y condiciones económicas y financieras (art. III-6).

\subsection{Externalización de la prestación del servicio}

En Economía se denominan externalidades a los «costes de una transacción que recaen sobre los miembros de la sociedad, o beneficios que son re-

106 CABallero SÁnchez, R., Infraestructuras en red y liberalización de servicios públicos, Madrid, INAP, 2003, p. 370. RICHER, L., «Droit d'accès et service public», en AJDA, 2, 2006, pp. 73-79. 
cibidos por ellos, pero que no son tenidos en consideración por las partes de una transacción» ${ }^{107}$. La externalidad alude a un beneficio o perjuicio que para el individuo o la empresa representan las acciones de otras personas o entidades por los ahorros de costes, el beneficio de la especialización, la mayor eficiencia por la modernización de los procesos productivos y la flexibilidad en la disposición de recursos.

También se entiende por externalización al proceso empresarial de «transferir al exterior de una empresa actividades internas recurrentes», que «permite [...] explotar simultáneamente sus ventajas competitivas y obtener una mayor variedad de productos y servicios». Se ha definido como «una relación contractual entre un vendedor externo y una empresa, en la que el vendedor asume la responsabilidad de una o más funciones que pertenecen a la empresa ${ }^{108}$. Los principios determinantes son la separación técnica e institucional, el grado de estandarización de las tareas, los costes de transacción y gestión y el nivel del mercado ${ }^{109}$. Se realiza en una unidad productiva autónoma de carácter industrial (montajes y premontajes o actividades intermedias) o logística a la que se encomiendan funciones no vitales o esenciales (actividades core).

La externalización empresarial recurre a un suministrador ajeno especializado, interior (outsourcing) o exterior (offshoring), para que realice total o parcialmente algunas funciones integradas o integrables en su proceso productivo o actividad durante una periodo de tiempo. Forma parte de un proceso estratégico en el que se persiguen objetivos de incremento de valor y ventajas de competencia. Exige un compromiso contractual claro y equilibrado que distribuya las funciones y las responsabilidades, las condiciones, los precios y la valoración de los resultados, la confidencialidad, la distribución de las ventajas de productividad y las condiciones de reversibilidad. Supone una cultura empresarial compartida en cuanto a organización, innovación, flexibilidad sobre la evolución de las aportaciones de todos los implicados en formación y competencia.

Se distingue entre la contratación de capacidad o concurrente temporal dentro del mismo sector empresarial, la comunitaria para el reparto de las actividades correspondientes a materias diferentes con una dirección y proyecto común, y la especializada para recibir actividades especiales que son necesarias o complementarias a la actividad principal. Esta última es la externalización propiamente dicha que, si produce los beneficios derivados de no tener que invertir o equiparse para ello, tiene costes de transacción (búsqueda de los suministradores, de negociación, de producción y transporte,

\footnotetext{
107 Lipsey, R. G., Introducción a la Economía positiva, Barcelona, Vicens Vives, 1991, p. 917.

108 White, R. y James, B., Manual de Outsourcing: Guía completa de externalización de actividades para ganar competitividad, Barcelona, Ediciones Gestión 2000, 2003, p. 15.

109 Proulx, P.-P., «L'externalisation de la production de biens et services: contexte, définition et effets économiques sur le pays d'origine et d'accueil», en Cahiers de recherche, Montréal, Centre Études internationales et Mondialisation, 2006, pp. 5-9.
} 
etcétera) y costes de coordinación interna, aunque la responsabilidad del almacenamiento y de la entrega en tiempo preciso (jus in time) corresponde al suministrador.

A la externalización empresarial se le reconocen las siguientes dimensiones. En la económica en cuanto reduce costes, optimiza los intercambios, mejora los procesos y prácticas, la productividad y la competitividad, aumenta la concentración en el aspecto principal de la actividad, reduce las inversiones y desarrolla actividades de mayor valor añadido. En el orden tecnológico aporta mayor información y permite elegir la mejor opción, respeta los estándares específicos, produce flexibilidad e innovación, garantiza el mejor resultado y calidad. Es un fenómeno común a la actividad económica empresarial cada día más centrada en su actividad esencial, encomendando a otras empresas ajenas las actividades que afectan al proceso de producción (logística, mantenimiento), las funcionales (informática, contabilidad y gestión de personal), servicios generales (limpieza, restauración, seguridad, etcétera).

Cuando se habla de externalizar la actividad de la Administración se incluyen, en sentido amplio, todos los supuestos en que los particulares ejercen funciones públicas o gestionan servicios públicos. Sin embargo, en un sentido estricto, la aplicamos a los supuestos en que la Administración, titular de la competencia y gestora de la misma, decide confiar a otra organización pública o privada, con o sin ánimo de lucro, la prestación de servicios, que no son funciones fundamentales y que pueden realizarse a menores costes y con la misma calidad ${ }^{110}$. Son razones fundamentalmente económicas, de ajustes presupuestarios, prioridades en el gasto público, reducción de costes, racionalización de efectivos y eficacia las que la justifican y conducen a reducir los elementos temporales, por no sustanciales, que se han venido añadiendo ${ }^{111}$.

También se encuadra dentro de la tendencia a la descentralización frente a la concentración centralizadora, llena de ineficacia y de consumo de recursos, que conduce a la creación de nuevos ámbitos externos de poder de decisión y a la reducción del espacio central del poder y la gestión públicos, así como a incrementar el protagonismo de los agentes privados en todos los campos de la actividad, basándose en el principio de subsidiariedad ${ }^{112}$.

OSBORNE y GAEBLER consideraron que el buen gobierno consiste en la posibilidad de contratar, delegar y establecer nuevas regulaciones. Estudiaron la externalización como modo de gestión de los servicios públicos esta-

\footnotetext{
${ }^{110}$ Rosenbaun, A., «La prestation de service concertée: La dynamique de la collaboration entre le secteur public, le secteur privé et la société civile», en Revue Internationale des Sciences Administratrives, 1, 2006, pp. 45-58.

${ }_{111}$ Pina, V., Torres, L. y Acerete, J. B., La iniciativa privada en el sector público: externalización de servicios y financiación de infraestructuras, Madrid, AECA, 2003.

112 Ortiz DíAz, J., «El horizonte..., cit., pp. 91-98.
} 
bleciendo sus fundamentos básicos a partir del análisis de la gestión local norteamericana. La labor directiva de la Administración en el establecimiento de las políticas, la obtención de los recursos para pagar los servicios, establecer las reglas para su prestación, calidad y control, así como su posterior evaluación, sin proceder a su prestación directa, «porque los gobiernos no tienen la obligación de suministrar los servicios, sino de vigilar para que existan», de modo que «los gobiernos emprendedores funcionan fundamentalmente como compradores hábiles, orientan a los productores para atender a sus objetivos estratégicos». Eso conlleva que los poderes públicos se concentran en la gestión y no se ocupan de la prestación directa que se encomienda al sector privado o al sector no lucrativo considerado «privilegiado para proporcionar bienes colectivos». Consideran que existen tres tipos de relación externa: sector público con sector privado, sector privado con sector privado y sector público con sector público ${ }^{113}$.

Del mismo modo que el de privatización, la externalización es un concepto económico que introduce el principio de competencia para favorecer la rentabilidad y calidad del servicio. Se diferencia de la primera en que la Administración sigue siendo la titular y gestora por medio de la planificación, el encargo, el control y la evaluación de la prestación realizada por otro agente. Persigue racionalizar y reducir los costes, mejorar la eficacia y la productividad de los recursos públicos, incorporación de nuevas tecnologías, complejidad de instalaciones y su mantenimiento, fundamentalmente las relacionadas con la información y las comunicaciones. Se considera que existen economías si el nivel del servicio proporcionado es igual o superior con menor coste.

Se tiende a encomendar funciones no esenciales o secundarias para poder concentrar sus recursos sobre los aspectos fundamentales, más importantes, o de más valor añadido, evitando la dispersión del esfuerzo. En este sentido el gobierno de Ontario (Canadá) ha establecido los siguientes principios para la elección de los modelos de prestación de servicios: «El gobierno no realiza la prestación directa salvo que sea el mejor modo de servir al interés público. Gestiona la prestación de los servicios como una empresa. Si no existen razones decisivas a favor de la prestación directa, el gobierno examinará nuevos modelos, sobre todo con una mayor participación del sector privado» ${ }^{114}$.

Se ha iniciado en el funcionamiento de establecimientos públicos destinados a adquirir, preservar, estudiar, interpretar y hacer accesible al público (para su formación u ocio) objetos, documentos, inmuebles y terrenos con valor

\footnotetext{
113 Osborne, D. y Gaebler, T., Reinventing Government: Hot the Entreprenuerial Spirit Is Transforming the Public Sector, Reading, Mass., Addison-Wesley, 1992, pp. 30, 35, 44 y 84-89. Versión española: La reinvención del Gobierno, Barcelona, Piados, 1994.

114 Gouvernement d L'Ontario, Cadre d'examen de nouveaux modes de prestation des services, Secrétariat du Conseil de gestion, 2996, p. 7.
} 
educativo y cultural en el plano artístico, científico, histórico, natural o técnico (museos, bibliotecas, etcétera). Posteriormente, se ha pasado a la prestación de servicios públicos gestionados por la Administración titular de la competencia en la materia.

Según DRUCKER, la externalización es un proceso creciente día a día y que se produce cuando «una empresa, un hospital o una administración confía toda una actividad a una firma independiente especializada en un tipo de tareas. [...] En diez o quince años se habrán externalizado todas sus labores de mantenimiento que no producen directamente cifra de negocio, así como todas las actividades que no ofrezcan oportunidades de promoción. Dicho de otro modo, la mayoría de las personas que trabajarán en la empresa o los administradores puede que no sean asalariados, sino que formen parte del personal de una empresa contratante» ${ }^{115}$.

Para la American Mangement Association «la externalización consiste en recurrir a un organismo exterior para la prestación de un servicio [...] Exige una inversión a largo plazo en una relación con un tercero que debe ser ventajosa para ambas partes» ${ }^{116}$.

DUNKLE la define como «recurrir a la experiencia y a los recursos de un organismo exterior que asumirá la responsabilidad completa o parcial de una función ejecutada antes internamente; o la compra a un suministrador exterior de bienes y servicios que un organismo producía suministraba el mismo antes» ${ }^{117}$.

Siguiendo el modelo de las empresas, la externalización en la Administración es más compleja que en aquellas, porque no se utilizan sólo criterios de rentabilidad económica. Necesita un proceso de formación y experiencia para establecer las bases, la dirección, el control, la supervisión y la evaluación de los resultados y de la calidad de los servicios prestados. Por parte de las empresas exige una experiencia en la gestión, una capacidad de innovación tecnológica y, en particular, el conocimiento de los fines de los servicios y de su régimen administrativo, muy distinto de la relación empresarial. La dificultad es menor cuando se trata de gestionar funciones instrumentales no esenciales, que son comunes o con pequeñas variantes respecto al mundo empresarial, que exige una previa delimitación entre las distintas funciones y actividades administrativas.

En todo caso se debiera excluir de la externalización aquellas funciones esenciales y las que implique el ejercicio de potestades o funciones superio-

\footnotetext{
115 DruCKer, P.F., «Structures et changements: balises pour un monde différent», en Village mondial, 1996, pp. 69-70.

116 JACKSON, J., «Outsourcing», en AMA Management Handbook, American Management Association, 1994, pp. 9-52.

117 DunkLe, C.B., «Outsourcing the Catalogue Department: A Meditation Inspired by the Business and Library Literature», en Journal of Academic Librarianship, 1, 1996, pp. 33-34.
} 
res directivas ${ }^{118}$. Aquí situaríamos las de decisión política, las de poder público, las discrecionales, las de garantía de derechos. Sin embargo, no siempre ha sido el criterio de la potestad (puissance publique) el diferenciador de lo que sea o no esencial en función del ejercicio de loas prerrogativas, porque en algunos países de la se han externalizado actividades propias del poder público como las prisiones (EEUU, Canadá, Reino Unido y Australia) o los servicios de socorro e incendios (Dinamarca) ${ }^{119}$.

A la hora de decidir sobre la externalización de la prestación de un servicio no esencial suelen predominar dos criterios. El primero es de la adecuación al conocimiento y a la innovación tecnológica que exige inversión previa en el proceso de su diseño y un proceso continuo de adaptación y especialización con mayor agilidad que la proporcionan los sistemas administrativos. El segundo es el relativo a la reducción de los costes para poder utilizar de forma más eficiente los recursos públicos limitados. Aquella se basa en la capacidad del sector privado en reducir las necesidades de personal, principalmente en las funciones administrativas y supervisoras, en su mayor productividad; en los menores costes laborales y de seguridad social; la posibilidad de que entidades sin ánimo lucrativo pueda realizar su labor de modo desinteresado; las economías de escala y costos por la amplitud de su sistema de prestaciones y dirección centralizada, así como los menores costes generales y la mayor capacidad productiva.

La externalización se considera como uno de los medios de las estrategias de reforma de la Administración para que sea más activa, eficaz y eficiente, mejor gestionada y más atenta a las demandas de la sociedad, porque permite reducir las estructuras administrativas, mejorar sus métodos de trabajo, descargarlas de funciones no sustantivas a su competencia, modernizar los servicios y reducir sus costes de funcionamiento, mejorar la productividad e introducir conceptos como los objetivos, resultados, etcétera ya aplicables en las empresas.

Se han de señalar algunos inconvenientes que se derivan de la externalización como son el rechazo social por parte de las organizaciones sindica$\operatorname{les}^{120}$ y los agentes políticos situados en opciones de izquierda, defensores a ultranza de la presencia y gestión públicas y directas. Los primeros, además de los puros criterios corporativos, argumentan con los segundos su carácter neoliberal y conservador, destructor del Estado social, sin tomar en consideración que es lo contrario, un medio de seguir manteniendo sus presta-

\footnotetext{
118 Martín, L.L., «Bindding on Service Deluvery: Public-Private Competition», en International City/ Country Management Association, Management Information Servicde Reports, 25, 11, 1993, p. 3, establece una parrilla de evaluación de los servicios de la ciudad de Indianápolis a efectos de su privatización y distingue entre los servicios esenciales no externalizables (seguridad pública, incendios y Tribunales) y los servicios auxiliares susceptibles de serlo.

119 OCDE, Moderniser l'État: la route à suivre, Paris, 2005. Los EEUU haun utilizado «ejércitos privados» en labores de penetración y acciones subversivas en territorios enemigos.
} 
ciones con la eficacia gestora privada en un momento de reducción de los medios económicos estatales y de apertura a la competencia ${ }^{121}$. Actualmente «lo decisivo no es quien preste el servicio sino que éste promueva la libertad solidaria de los ciudadanos o, si se quiere, posibilite un mejor ejercicio de los derechos por parte de las personas. Es decir, que incida favorablemente en las condiciones de vida de las personas y promueva la elección de los servicios» ${ }^{122}$.

Por otra parte, es precisa una detallada información de costos-beneficios anteriores y posteriores para no dar lugar a que, finalmente, no se produzcan ventajas en los primeros y, por el contrario, se reduzca la calidad y satisfacción de los segundos. También el régimen de contratación administrativa puede crear dificultades si los contratos no son posibles a largo plazo y con compromisos presupuestarios asegurados, porque la externalización sólo se puede evaluar a largo plazo y crea rigideces presupuestarias. El adjudicatario de la prestación de los servicios puede temer que afecten a su actividad en el orden mercantil (concursos, impagos, etcétera), laboral (huelgas, despidos, etcétera), de capacitación profesional de su personal, de calidad, intrusismo, abuso de confianza, etcétera sobre los que la Administración no tiene competencia. Por otra parte, la convivencia de personal de distinto origen y régimen jurídico, económico y laboral suscitan tensiones y dificultades. Mayores riesgos suponen el acceso a los sistemas de información y comunicaciones que pueden afectar a la confidencialidad documental por acceso a las bases de datos o documentos, situación que puede producirse, incluso, con los arrojados a las papeleras ${ }^{123}$.

También se han diagnosticado riesgos de corrupción en los factores intervinientes por la insuficiencia de las reglas contables y de relación (condiciones contractuales y de los pliegos de condiciones), clientelismo en las adjudicaciones por influencia y capacidad de presión de grupos de intereses no necesariamente económicos, debilidad de los instrumentos públicos de seguimiento y control, cláusulas de salvaguarda insuficientes sobre la garantía de la prestación y sus condiciones y dejación por los funcionarios de sus labores ${ }^{124}$.

\footnotetext{
120 Internationale des Services Publics, Le dilemme public-privé: questions et aspects pratiques soulevés par les syndicats, 2002.1, www.world-psi.org.

121 RAMIÓ Matas, C., «Corrientes neoempresariales versus corrientes neopúblicas: cultura administrativa, valores públicos y credibilidad social. Un planteamiento radical», en Instituciones y Desarrollo, $5,1999$.

122 Rodríguez-Arana, J., «Servicio..., cit., p. 385.

123 Echevarria, K., Mas, J., Ramió, C., Santolaria, J., Brotons, J. y Freixa, C., Guia per a l'externalització y l'avaluació de la gestió privada de serveis públics, Barcelona, Generalitat de Catalunya, 1997.

${ }^{124}$ MAdRID JuAN, J., «Recomendaciones de la OCDE sobre pagos ilícitos en las transacciones económicas internacionales», en Información Comercial Española, 741, 1995, pp. 47 y ss. RoDRÍGUEZ-ARA-
} 
Para compensar el efecto de la pérdida de control público se han de excluir los servicios esenciales y se han de establecer técnicas de control sobre los externalizados con técnicas de planificación, calidad, rendimiento, vigilancia, sanciones por incumplimiento, inspección de la calidad, etcétera. Todas ellas orientadas a garantizar el control permanente, la calidad de las prestaciones y a evitar la dependencia, demostrando que la titularidad y la gestión son públicas. A ello pueden ayudar la cooperación interadministrativa y la puesta en común de experiencias en la materia.

Sirva de ejemplo que la Comisión europea estableció que, a partir del 1 de enero de 2003, se externalizasen trabajos administrativos de gestión ordinaria como la administración de las remuneraciones y las infraestructuras con el fin de racionalizar las actividades internas e incrementar la eficacia de los servicios. En el ámbito de la defensa durante la guerra de Irak se han exteriorizado por los EEU y el Reino Unido numerosos servicios dejando a las fuerzas militares en su labor propia ${ }^{125}$. En Francia el Estado Mayor de los Ejércitos, el Ministerio de la Defensa y otros organismos celebraron en abril de 2002 una jornada sobre la política, la cultura y la estrategia de la externalización en el marco de la Ley de Programación Militar de la que constituye un eje estratégico para la modernización del Ministerio y la profesionalización de los ejércitos. Es un efecto de las nuevas formas de conflicto, de la desaparición del servicio militar obligatorio y la profesionalización, de la innovación tecnológica y de la necesidad de hacer más eficientes los recursos presupuestarios disponibles. El proyecto de Carta de la externalización del Ministerio de Defensa francés define como principios de una buena externalización:

a) Su integración en una perspectiva estratégica: consiste en confiar todo o parte de una función o de una prestación de servicio a un agente especializado, por una duración plurianual, con obligación de resultados. Este se compromete a suministrar la prestación conforme al nivel de servicio, de resultado y responsabilidad establecidos.

b) Implica una participación: la búsqueda permanente de innovación, de flexibilidad y de reactividad se inscribe en una perspectiva de continuidad de las colaboraciones y de evolución de los oficios y las competencias de los colaboradores. El conocimiento compartidos de las organizaciones y oficios en el respeto de la cultura de cada uno permite organizar mejor los intercambio para enriquecer la prestación y beneficiar las competencias de cada uno de los partícipes.

c) Precisa un compromiso contractual claro y equilibrado: se apoya en contratos que comprometa a los socios a largo plazo tomando en cuenta las

NA, J., Principios de ética pública. ¿Corrupción o servicio?, Madrid, Montecorvo, 1993. SÁncheZ Morón, M., «La corrupción y los problemas de control de las Administraciones públicas», en LAPORTA, F.J. y Álvarez, S., La corrupción política, Madrid, Alianza, 1977.

125 Leymarie, P., «Défenses européennes en voie d'externalisation», en Le Monde diplomatique, noviembre 2004, p. 28. 
obligación de reacción y adaptación de cada uno. El contrato de servicio plurianual precisa la distribución de funciones y responsabilidades, prevé la posible evolución de las prestaciones, fundamentalmente en el cuadro específico de las operaciones exteriores, las modalidades de fijación de los precios y de valoración de los resultados, la confidencialidad de la información, las cláusulas penales, de participación en beneficios y de las condiciones de transferencia.

d) Pone a la persona en el centro de la gestión: la gestión se apoya en la comunicación, el diálogo, la formación, la integración, la fidelización, la evolución profesional por el continuo desarrollo de las competencias de los colaboradores afectados.

e) Se apoya en una organización flexible y próxima: requiere una organización capaz de reaccionar respecto al prestatario y el cliente que garantice a todos los niveles la expresión de las necesidades y su satisfacción, identificando el reducido equipo de decisión de la estructura en los aspectos decisorios, operativos, técnicos y jurídicos durante todo el proyecto, así como un dispositivo que le garantice conocer la experiencia e información de la calidad y la satisfacción proporcionadas ${ }^{126}$.

\footnotetext{
${ }^{126}$ Mouvement des Entreprises de France-MEDEF-Comité de Liaison Défense, Ministère de la Défense, Institut Esprit Service, Actes du colloque, Perspectives d'externalisation en France, 11 de abril de 2002, institut-esprit-services.medef.fr/doc/actes_defense.pdf.
} 